\title{
Human and Social Capital Complementarities in the Presence of Credit Market Imperfections
}

\section{Natasha Moeen*}

\begin{abstract}
This paper models the individual-level social capital effect the credit market constraints that reduce the accumulation of costly human capital. Human capital, in turn, improves an individual's income as well as the bequest that they intend to leave for their children. It also helps reduce inequality across a country. Finally, the model shows that investment in social capital has a negative relationship with the interest rate, so that the initial inherited bequest of every individual affects the output and investment in the short-run, as well as in the long-run.
\end{abstract}

Keywords: Social capital, credit market, investment, interest rate.

\section{JEL classification: E24.}

\section{Introduction}

The significance of educational credentials for an individual's job market success is well established in labor economics. These market returns, which are realized in the future, incentivize individuals to accumulate human capital today. Spence's (1973) job marketing signaling theory reinforces the idea that education signals help employers identify the most productive employees. The direct effect of human capital on productivity is confirmed by Lucas (1988), Romer (1989) and Dinda (2008). The indirect effect through spillover has been shown by Nelson and Phelps (1966), and Becker and Mulligan (1997). This paper analyzes the role of individual-level social capital accumulation in easing the credit market constraints, which facilitate the accumulation of costly human capital and reduces income inequality.

Social capital has been described in various ways throughout the economic literature. Van Staveren and Knorringa (2007) find that relations matter though it is difficult to know all the factors that affect the productivity of individuals (Imandoust, 2011). Social capital is acquired by the repeated interaction of at least two people with the expectation of receiving mutual benefits in the future. Various strands of literature discuss the effect of social capital on economic growth (Putnam \&

\footnotetext{
* Teaching Fellow, Faculty of Economics, Lahore School of Economics, Pakistan.
} 
Helliwell, 1995; Knack \& Keefer, 1997; La porta et al., 1999 Chou, 2006; Dincer \& Uslaner, 2010). However, the measurement of social capital varies since there is no perfectly generalizable variable.

Social capital accumulation is prioritized as it inculcates trust and understanding among people, which creates incentives for everyone to efficiently achieve a common goal. Potential benefits of social capital under discussion here will be with regards to material goods and services, including children's health care (Kawachi et al., 1997), information flow regarding the credibility of borrowers (Knack \& Keefer, 1997; Putnam, 2000), trust formation for better access of credit (Duffhues \& Weterings., 2011), reduced transaction costs (Coleman, 1988; Dinda, 2008) and complementing other capitals such as human capital (Coleman, 1988; Becker, 1994; Coleman, 1994; Glaeser et al., 2002. Besides the above mentioned monetary benefits, there are some non-monetary benefits attached to social capital accumulation, such as moral support for psychological happiness (La Porta et al., 1999).

The accumulation of social capital requires constant maintenance, or it will diminish like human capital. Becker (1964) posits that when an individual leaves a job, all the social capital gained horizontally or vertically is reduced over time. Therefore, a variable such as homeownership is a good indicator of whether one is likely to invest in one's social capital and unlikely to migrate (Glaeser et al., 2002). Physical distances determine social connections; therefore, the non-monetary cost of social exclusion is significant.

This paper aims to fill the gap in literature by modelling financial development with the help of social capital accumulation. Our focus is on two types of income groups: those who can afford costly education, and those who cannot given the bequest that they inherit from their parents. Empirical literature gives us inspiration as the vertical link between the two income groups can solve the problem of credit market constraint (Duffhues \& Waterings, 2011). When low-income groups pursue loans to finance education, their credibility is usually unknown to the lenders which creates the problem of asymmetric information. Hence, the borrowers pay large interest rates on loans which include the borrowing cost as well as the monitoring costs borne by the lenders. In this model, income is examined in three components: consumption, bequest, and social capital. Consumption and bequest are discussed in the model by Galor and Zeirra (1993), whereas individual social capital has been discussed in the model by Glaeser et al. (2002). We do not believe that social capital has been 
discussed in conjunction with the first two components in any model in the literature. In order to induce the efficient allocation of capital, we set up an economy in which individuals invest in social capital accumulation to bypass high monitoring costs. These financial arrangements change the incentives and constraints that the economic agents would face. This paper builds a theoretical model where individual level social capital accumulation helps lower the borrowing rates so that more skilled individuals can enter the labor force in the long-run.

This paper adds to the existing theoretical framework in two ways. First, it develops an explicit relationship of social capital with income, unlike the implicit relationship described in the literature. Second, it shows that for interest rates to vary for low-income borrowers, social capital accumulation is essential, as the individual aspect is being considered rather than aggregate. The model's results show that the interest rate is dependent upon social capital; therefore, higher social capital allows individuals to borrow at a lower rate when compared to what is offered in the market. Also, our model assumes that borrowers' costs are dependent upon the mobility cost of individuals. Individuals with sufficient social capital typically will not attempt to migrate as their movement will affect those relationships, and the borrowing cost will eventually increase due to monitoring becoming difficult for the lenders.

The following section describes the economy being modelled by specifying an individual's behavior and the incentive compatibility constraint they face. We describe various components of one's income and how a budget is optimally allocated for consumption, bequest and social capital. We then discuss how social capital accumulation lowers interest rates as compared with the market interest rates. We then solve for various threshold levels of bequest and define the region where agents are charged a lower interest rate with social capital accumulation. We have also perform a comparative static analysis on long-run equilibrium to see which economies would benefit the most in the future.

\section{Description of the Economy}

To account for the prevailing problem of risk, which is developed through trust and investment in social capital, we build an overlapping generations model (OLG), wherein there is a continuum of individuals of size, $L$, who live for two time periods. Our model settings and assumptions are based on the papers of Galor and Zeira (1993) and Glaeser, Laibson and 
Sacerdote (2002), as we explore the theoretical linkage between an individual's initial inheritance and human capital via social capital accumulation.

\subsection{Benchmark Model}

It is assumed in this model that a small open economy produces only a single product. Each individual then decide how they wish to utilize this product - consumption or further investment. The good's production is carried out through two technologies. Two methods are employed for the good's production.

The first method uses unskilled labor, which is defined as:

$$
Y_{t}^{u}=w_{u} \cdot L_{t}^{u}
$$

where $Y_{t}^{u}$ is the unskilled output, $L_{t}{ }^{u}$ unskilled labor and $w_{u}$ is the unskilled wage rate or the marginal productivity of labor. Also, $w_{u}>0$ is used for anyone who works as an unskilled laborer.

The second method uses skilled labor as well as capital and is defined as:

$$
Y_{t}^{s}=f\left(L_{t} s, K_{t}\right)
$$

where $Y_{t}^{s}$ is skilled output, $f$ is a concave function with constant returns to scale, $L_{t}^{s}$ is skilled labor, and $K_{t}$ is the capital used in the production of this product. We assume that the technology used in the production of the good requires skill and knowledge; hence, the inclusion of physical capital only in the production of skilled output production function.

Taking the assumption from Galor and Zeira (1993), the investment in physical capital is made a period before, like human capital accumulation, and for model simplification it does not depreciate over time. The number of skilled individuals is anticipated because investment in human capital occurs one time period earlier, and their wage is dependent upon the lending rate and the level of technology. Due to this known number of skilled individuals entering the workforce, the capital-labor ratio remains constant along with the wage rate, $w_{s}$. Lastly, we assume that the labor and goods market described above are perfectly competitive. 


\subsection{Individuals}

The economy contains agents living two periods with intergenerational altruism. Parents care about their children's well-being so they leave a certain bequest for them to be consumed in future. In time period 1, the individual is young and in time period 2, the individual is old. Parents care about their children and leave a certain amount, $b_{t+1}$, to their children according to their resources. We assume that population growth is constant with one parent and one child which creates a link between the two generations. Individuals within each generation are homogenous in terms of their preferences and innate abilities; they are heterogeneous in terms of the level of the initial bequest which they receive from their parents. Every agent is endowed with one unit of time in every period. When young, he/she allocates his/her time; receiving education, working and accumulating social capital, while the old agents can only utilize their time working in either skilled or unskilled labor depending upon the decisions made the first time period.

If agents do not acquire education in time period 1, they work as unskilled labor in time period 2. Individuals work as a skilled laborer in time period 2 only if costly human capital, $h$, is accumulated in time period 1. Human capital cost includes a fixed amount for tuition fee and other complementary expenditures. In the real world, this cost is divided by giving weight to each class of labor associated with the process of human capital acquisition. For instance, the weight given to skilled teachers is higher compared to the unskilled janitors working in the school. For model simplification, we are using the combined cost of human capital. Whether an individual joins the labor force as a skilled or unskilled laborer is dependent upon the initial conditions of each individual. For the sake of model simplicity, we take the assumption from Galor and Zeira (1993) that consumption only occurs in time period 2.

\subsection{Preferences and Budget Constraint}

We assume that the preferences and abilities of agents are identical for time period, $t$. Agents allocate their income toward domestic consumption for adulthood, intergenerational funds in the form of bequest for their children, and productive social capital which has defined returns. These preferences are described in log-linear utility function as:

$$
U_{i, t+1}=\alpha \log \left(c_{t+1}\right)+\beta \log \left(b_{t+1}\right)+(1-\alpha-\beta) \log R(\hat{S}) \cdot S i_{t+1}
$$


where $\alpha \in(0,1), \beta \in(0,1)$

Equation (3) shows the log utility of an individual for a time period, where $c_{t+1}$ represents consumption in time period $2, b_{t+1}$ is the level of inherited bequest received from their parents and $R(\hat{S}) \cdot S_{t}{ }^{1}$ is the return on social capital which everyone receives by investing in it.

Glaeser et al. (2002) define the variable $R(\hat{S})$ as the market and nonmarket returns individuals receive from investing in social capital. Monetary or market returns include better employment opportunities when one becomes skilled. This phenomenon is expected because when an individual has strong connections and information about the job vacancy, the chances are higher that he/she will successfully obtain their desired job (Leana III \& Van Buren, 1999; Lin., N 2000) when compared to the individual with weaker connections. Likewise, non-monetary or nonmarket returns include subjective motives like happiness from relation building and improvement in health. $\alpha$ and $\beta$ are the weights assigned to consumption, and $(1-\alpha-\beta)$ is the weight assigned to the individual-level social capital of each individual. He/she then chooses his/her optimal level of consumption, level of bequest and investment in social capital which maximizes utility.

The budget constraint of an individual from generation $t$ in time period $t+1$ is:

$$
y_{t+1} \geq c_{t+1}+b_{t+1}+\gamma_{i} S_{t+1}
$$

where $\gamma \epsilon(0,1)$ and is dependent on index $i$.

From equation (4) we see that the income of individuals, $y_{t+1}$, in time period 2 (when they become adults) is constrained by the household consumption, the bequest for their offspring and the cost of social capital.

The proportion of income spent on consumption will be categorized as non-productive, whereas the proportion of income spent on social capital is productive, with the bequest being utilized as savings by the next generation. Higher consumption leads to an improved standard of living for the low- and high-income groups in the society. Spending can be on infrastructure, modern sanitation \& water facilities, or on desirable food products (Dasgupta \& Maler, 1995). However, marginal utility from

\footnotetext{
${ }^{1}$ This function, $\log R(\hat{S}) . S_{i, t+1}$ is identical to that of Glaeser, E. et.al (2001). An economic approach to social capital. The Economic Journal, 112(483), F437-F458.
} 
consumption by the low-income group is greater than that realized by the high-income group, even if spent on the same products.

In our model, individual investment in social capital is defined as spending time with family and friends (e.g., helping in times of crisis, paying a visit, or simply calling to socialize). Therefore, we also assume that the time cost of accumulating social capital is proportional to one's income as stated by Glaeser et al. (2002). This implies that the unit of time spent on social interaction, away from work, may cost more for skilled individuals than unskilled individuals with lower opportunity cost of time. Skilled people earning higher wages value their time more as they can be more productive than unskilled people given the same unit of time. Thus, individuals bear $\gamma w_{s}$ and $\gamma w_{u}$ which are the costs of skilled and unskilled workers respectively.

\subsection{Optimization}

Individuals maximize their utility function in equation (3) subject to the budget constraint in equation (4). Thus,

$$
\begin{aligned}
& \operatorname{Max} U_{i, t+1}=\alpha \log \left(c_{t+1}\right)+\beta \log \left(b_{t+1}\right)+(1-\alpha-\beta) \log R(\hat{S}) \cdot S_{i, t+1} \\
& c, b, S_{i}
\end{aligned}
$$

subject to:

$$
y_{t+1}=c_{t+1}+b_{t+1}+\gamma_{i} S_{t+1}
$$

By setting up a Lagrange, we find the first-order conditions².

By solving the first-order conditions, we find the optimal values:

$$
\begin{aligned}
& c_{t+1^{*}}=\alpha y_{t+1} \\
& b_{t+1} * \beta y_{t+1} \\
& S_{t+1^{*}}=\frac{(1-\alpha-\beta) y_{t+1}}{\gamma_{i}}
\end{aligned}
$$

By substituting for $\left(\gamma_{i}\right)$ optimal social capital for skilled and unskilled labor is defined according to their wage rate as:

\footnotetext{
${ }^{2}$ For detailed working, see Appendix A
} 


$$
\begin{aligned}
S_{i}^{u} & =\frac{(1-\alpha-\beta) y_{t+1}}{\gamma w_{u}} \\
S_{i}^{S} & =\frac{(1-\alpha-\beta) y_{t+1}}{\gamma w_{s}}
\end{aligned}
$$

From their income, a fixed fraction of $\alpha$ is allocated to household consumption, a fraction of $\beta$ is allocated for intergenerational transfers, while the remaining fraction $(1-\alpha-\beta)$ of income per respective cost (proportional to one's income) is allocated to optimal social capital accumulation.

By substituting for the optimal values from equation (5), (6) \& (7), we find an indirect utility function, $V_{t}{ }^{2}$ :

$$
\begin{aligned}
& V=\alpha \log (\alpha)+\alpha \log \left(y_{t+1}\right)+\beta \log (\beta)+\beta \log \left(y_{t+1}\right)+(1-\alpha-\beta) \log R(\hat{S})+(1-\alpha- \\
& \beta) \log (1-\alpha-\beta)+(1-\alpha-\beta) \log y_{t+1}-(1-\alpha-\beta) \log \gamma \\
& V t=\log y_{t+1}-(1-\alpha-\beta) \log \gamma_{i}+\varepsilon \\
& \text { where } \varepsilon=\alpha \log \alpha+\beta \log \beta+(1-\alpha-\beta) \log (1-\alpha-\beta)+(1-\alpha-\beta) \log R(\hat{S})
\end{aligned}
$$

\section{Credit Markets}

Due to imperfect information available to lenders regarding individual borrowers' credibility, the lending rate is higher than the borrowing rate in the credit market for individual borrowers. To account for this uncertainty, lenders' monitoring costs need to be positive to ensure that the borrowers do not default on their loans. This additional tracking cost must be covered by the lender so the lender will only lend at a rate greater than the risk-free interest rate, $r$.

Lenders have always been essential to the financial landscape. Therefore, it is important to classify the type of lenders on which our model focuses: anyone who can lend money to a person whose inherited bequest cannot cover human capital expenses. Thus, borrowed money in this model is assumed only to be spent on acquiring education to become skilled. This borrowing can be one-time or continued according to one's financial needs. Individuals may benefit from additional financial resources and secure their future by building the bequest. Whereas, the relationship with age is such that if an individual's peers die when he/she is old, there may be no one to look after him/her in times of need as the individual would have no additional resources. The interest rate is defined as:

$$
i=r+z \cdot f\left(S_{i}\right)
$$


where $i$ is the per unit interest rate which lenders charge. It is a sum of the risk-free per unit interest rate, $r$, along with the monitoring cost, $z$. Monitoring cost is a multiplicative function with $f\left(S_{i}\right)$. This function is linear with a negative relationship. As the investment in social capital increases, the interest rate on borrowings will be reduced as well as the monitoring cost, $\mathrm{z}$. The channel has already been discussed in this paper as relation building helps individuals develop trust amongst each other. The lenders then incentivize the borrowers by giving cheap loans where collateral is trust and loyalty. These loans are established through social capital investment.

We propose that an individual lender's monitoring cost varies with the social capital of each individual. Whenever a social agreement is made between parties, individuals make sure to repay their debts in order to maintain their reputation (Stiglitz, 1990). We assume that borrowers with a dense network of friends, colleagues and family have high social capital. Similar types of people form social groups, an idea known as assortative mating (Mare, 1991). In this case, individuals with high social capital are well-connected, signaling to lenders that they are credible. Therefore, their mobility cost will also be high compared to those who are less connected with their peers. Thus, lenders are better able to monitor the former category of borrower. Eventually, this decreases lenders' monitoring cost for borrowers who possess higher social capital. These costs may consist of travelling expenditures, public relations or plain psychological costs (loss of happiness that results from moving away from home). In order to discourage borrowers from evading debt repayments, lenders keep $z$ as high as possible.

The incentive compatibility constraint described in equation (10) shows that as the borrowed amount increases, the monitoring and nonmonitoring cost of evasion both rise and the corresponding tracking cost borne by the lender rises as well:

$$
d(1+i)=\beta m . . z f\left(S_{i}\right)+\beta_{n m} f\left(S_{i}\right)
$$

where $\beta_{m}$ and $\beta_{n m}$ are the monitoring and non-monitoring costs of evasion respectively and $d(1+i)$ is the interest charged on the amount borrowed. Also, $d=(b-h)$. This incentive compatibility shows that the individual will be indifferent if the total interest paid on borrowed amount is equal to the total cost of default in terms of monetary and non-monetary cost. 
$\beta_{m}$ has a negative linear relationship with social capital $\left(\beta_{n m}\right.$, and a positive linear relation with social capital. They are both multiplicative with social capital. Monitoring cost refers to the cost which lenders incur in order to verify the credibility of the borrowers (whether they will pay back the money or not). This is through repeated interaction which builds trust. These relations are either built intentionally (for instance, if lenders remain in touch with peers through frequent visits or phone calls) or unintentionally (for instance, if the borrower works for a third party but provides their services as a mediator to the lenders and leaves a positive impression). The non-monitoring cost of social capital is focused on the psychological cost where borrowers/lenders usually feel unhappy and disconnected if they migrate or move away from their current social circle. The individual faces a mobility cost in terms of spending more money to keep in touch with friends and relatives. Also, individuals may incur greater traveling costs to maintain their membership in a prominent society or to simply maintain good relationships. Individuals with higher social capital incur higher costs of each type.

In this setting, there are two players: the borrower as an agent (whose level of inherited bequest is smaller than the costly education) and the lender as a principal (whose level of inherited bequest is greater than the costly education and allocate their savings to the borrowers). If the principal is a financial intermediary, they will charge a higher interest rate which includes the lending rate as well as the cost of monitoring the borrower. Since borrowers are investing by building trust and social capital within their vertical links, this monitoring cost is reduced substantially. In this way, social capital investment creates incentives for the borrowers to a) borrow at a lower rate than the market, and b) invest in their costly education to become skilled in time period 2 .

Equation (10) depicts how individuals will be indifferent when they pay interest rate, $i$, on the borrowed amount as it equals the monitoring cost and non-monitoring costs borne by the lenders. Galor and Zeira (1993) discuss only a general monitoring cost. We have introduced a sub-division with functional characteristics of the monitoring cost having a negative relationship with social capital and a positive relationship between nonmonitoring (psychological cost) and social capital.

By solving for the incentive compatibility constraint using equations (9) and (10), we can find $i$ : 


$$
\begin{aligned}
& i=\frac{d+r \beta_{m}-\beta_{n m} \cdot f(S i)}{\left(\beta_{m}-d\right)} \\
& 1+i=\frac{\beta_{m}[1+r]-\beta_{n m} \cdot f(S i)}{\left(\beta_{m}-d\right)}
\end{aligned}
$$

The comparative static for $\frac{\partial(1+i)}{\partial S i}$ shows a negative relationship ${ }^{3}$. Equation (11) implies that the interest rate that a lender charges to individual borrowers decreases with individual social capital accumulation.

\section{Income of Individuals}

In time period 1 , individuals or agents acquire education and work in time period 2, receiving the wages as skilled laborers or they can work as unskilled laborers in both time periods, 1 and 2. It is dependent upon the inherited bequest and/or if they invest in social capital accumulation to become skilled/unskilled in time period 2.

\subsection{Income of an Unskilled Worker}

In time period 1, when an individual is a child, if he/she opts to work, his/her compensation will be that of an unskilled worker's wage rate, $w_{u}$. At the beginning of time period 1 , an individual receives a bequest from his/her parents, $b_{t}$. Individuals then decide whether to become skilled in the next time period or work as unskilled in both time periods. They then become borrowers if the bequest is less than the human capital cost.

For unskilled individuals who work in time period 1, their income consists of childhood savings $\left(w_{u}+b_{t}\right)$, capital gains on savings $\left(w_{u}+b_{t}\right) r$, along with their current wage, $w_{u}$ which they receive in time period 2 . Therefore, cumulative wealth of an unskilled individual in $t+1$ will be:

$$
y_{t+1}^{u}=b t(1+r)+w u(2+r) \cong y_{t+1}^{u}\left(b_{t}\right)
$$

\subsection{Income of a Skilled Worker}

In time period 1, when an individual is a child, if he/she opts to acquire education, he can then work as a skilled worker in time period 2 as an adult. His/her compensation will be that of a skilled worker's wage rate, $w_{s}$. In time period 1 , this individual receives bequest, $b_{t}$, from his/her parents. The level of bequest determines one's wealth for $t+1$.

\footnotetext{
${ }^{3}$ For detailed working, see Appendix B
} 
If the bequest is sufficient to cover $h$, when $\left(b_{t}-h\right)>0$, the additional funds are saved for time period 2. Therefore, the individual can afford to finance costly human capital and can lend the savings to make capital gains. Thus, income in $t+1$ comprises wage income, $w_{s}$, capital gains on savings, $\left(b_{t}-h\right) r$, in addition to the savings $\left(b_{t}-h\right)$ themselves.

When $\left(b_{t}-h\right)<0$, the additional funds are borrowed at an interest rate, $i$. In time period 2 , the individual has to repay the loan amount plus interest amount to the lender as they are unable to finance the entire cost of human capital. Thus, income in $t+1$ comprises wage income $w_{\mathrm{s}}$, net of additional borrowings and the interest charged on them, $\left(b_{t}-h\right)(1+i)$. Therefore, the wealth of a skilled worker in $t+1$ depends on the levels of $b_{t}$ that they receive:

$$
\begin{array}{ll}
y_{t+1}^{s}=\left(b_{t}-h\right)(1+r)+w_{s} & b_{t} \geq h \\
y_{t+1}^{s}=\left(b_{t}-h\right)(1+i)+w_{s} & b_{t} \geq h
\end{array}
$$

\section{Agents' Decision Problem}

Agents make a choice in time period 1 whether to accumulate human capital or not based on the initial inheritance level.

Individuals accumulate human capital only if the utility of being skilled $(b>h)$ is greater than that of being unskilled.

$$
\begin{aligned}
& \mathrm{V}_{\mathrm{s}} \geq \mathrm{V}_{\mathrm{u}} \\
& \log \left[\left(b_{t}-h\right)(1+r)+w_{s}\right]+\log (1-\alpha-\beta) \log R(\hat{S})-(1-\alpha-\beta) \log \gamma w_{s} \geq \\
& \log \left[b_{t}(1+r)+w_{u}(2+r)\right]+(1-\alpha-\beta) \log R(\hat{S})-(1-\alpha-\beta) \log \gamma w_{u} \\
& \frac{(b-h)(1+r)+w_{s}}{b(1+r)+w_{u}(2+\mathrm{r})} \geq\left(\frac{w_{s}}{w_{u}}\right)^{1-\alpha-\beta}
\end{aligned}
$$

\section{Proposition 1}

Equation (16) implies that if the optimal ratio of a skilled individual's income to an unskilled individual's income is greater than the ratio of their wages, they will invest in human capital and become skilled adults. ${ }^{4}$ This also implies that those individuals whose ratio of skilled income to unskilled income is less than the ratio of their wages,

\footnotetext{
${ }^{4}$ For detailed working, see Appendix C
} 


\section{they will not acquire human capital, and work as an unskilled laborer throughout their lives.}

The third group of individuals can borrow money to invest in human capital. Therefore, the interest charged to them can be reduced if they simultaneously invest in social capital as well.

Individuals accumulate social capital only if the utility of being skilled (b $<\mathrm{h}$ ) and borrowing at $(1+i)$, is greater than the utility of being unskilled.

$$
\begin{aligned}
& \mathrm{V}_{\mathrm{S}}^{*} \geq \mathrm{V}_{\mathrm{u}} \\
& \log \left[\left(b_{t}-h\right)(1+i)+w_{s}\right]-(1-\alpha-\beta) \log \gamma w_{s} \quad \geq \log \left[b_{t}(1+r)+w_{u}(2+r)\right]- \\
& (1-\alpha-\beta) \log \gamma w_{u}
\end{aligned}
$$

Simplifying the expression, we get:

$$
S^{*} \geq S^{u}
$$

Equation (17) gives a threshold level, $f$, above which all individuals invest in social capital to ease their credit constraint and invest in human capital. 5 This means indivisible education is limited to those individuals who can afford it completely or can borrow money by reducing their interest rate to become skilled in the future. This characteristic of indivisibility of human capital leads to multiple equilibria in the short-run and long-run.

Since the initial bequest level is the determinant of an individual's future occupation, we assume that, $I_{t}$, is the distribution of inheritance of all the individuals who are born in the first time period, $t$.

$$
\int_{0}^{\infty} d I_{t}\left(l_{t}\right)=L_{t}
$$

This distribution of inheritance decides the number of skilled and unskilled individuals that will be in labor force, $l_{t}$, of a respective economy such that:

$$
L_{t}^{S}=\int_{f}^{\infty} d I_{t}\left(l_{t}\right)
$$

is the skilled labor force, and

\footnotetext{
${ }^{5}$ For detailed working, see Appendix D
} 


$$
L_{t}^{u}=\int_{0}^{f} d I_{t}\left(l_{t}\right)
$$

is the unskilled labor force.

$I_{t}$ is the distribution of inheritance for all the individuals who are born in time period 1 and $L_{t}$ is the distribution of all the individuals who are in the labor force.

In Figure 1, we show that the shape of the distribution is a piecewise distribution: from threshold 0 to $f$ there is a linear upward sloping graph (point $\mathrm{f}$ is the inflection point since the second derivative is zero), from threshold $\mathrm{f}$ to $\mathrm{h}$, there is a convex upwards, and from $\mathrm{h}$ to $\infty$, there is a linear upward sloping function. For the entire distribution of individuals who are in the labor force, $L_{t}$, their distribution of inheritance, $I_{t}$, lies between 0 and $\infty$.

The results from the distribution demonstrate that from threshold 0 to $\mathrm{f}$, individuals work as unskilled laborers, and from threshold $\mathrm{f}$ to $\infty$, individuals work as skilled laborers. Note that this distribution will vary across countries due to credit market imperfections and how different individuals invest in social capital to finance their education through cheap loans. Due to the non-convexities and indivisibility of human capital investment, we will have multiple long-run equilibria for all countries.

\section{Social Capital Accumulation}

Individuals make decisions regarding optimal investment into social capital once they have internalized its benefits. From equation (7), we find the general form of optimal investment in social capital.

Therefore, we find the optimal investment by applying the value of (1+i) from equation (12):

$$
S^{*}=\frac{(1-\alpha-\beta)\left[(b-h)\left\{\beta_{m}(1+r)-w s\right\}+w s \beta_{m}\right]}{(b-h)\left[(1-\alpha-\beta) \beta_{n m}-\gamma w_{s}\right]+\gamma w s \beta_{m}}
$$

Social capital increases with a higher bequest level. When the second derivative is positive, the social capital for those who borrow to become skilled increases in a convex manner. ${ }^{6}$

\footnotetext{
${ }^{6}$ For detailed working, see Appendix E
} 
We can also find the optimal investment in social capital for an unskilled and skilled individual from equation (7.1 and 7.2):

$$
\begin{aligned}
S^{u} & =\frac{(1-\alpha-\beta)\left[b(1+r)+w_{u}(2+r)\right]}{\gamma w_{u}} \\
S^{s k} & =\frac{(1-\alpha-\beta)\left[(b-h)(1+r)+w_{s}\right]}{\gamma w_{s}}
\end{aligned}
$$

Figure 1

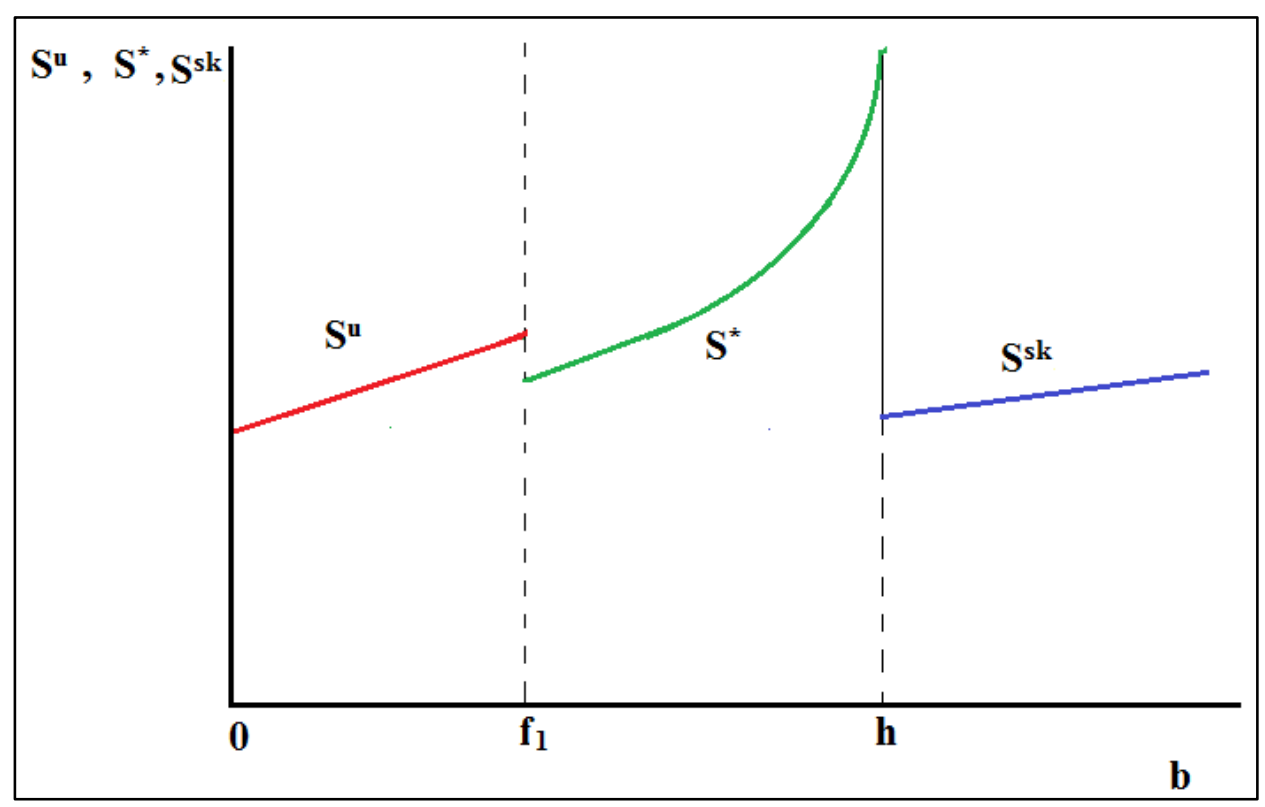

Source: Author's calculations.

Figure 1 shows the social capital for three individuals in the society. ${ }^{7}$ The three different portions show social capital of unskilled individuals, skilled borrowers and skilled individuals, respectively.

Since this expression was used to find the threshold $f, S^{*} \geq S u\left(\frac{w_{u}}{w_{s}}\right)^{\alpha+\beta}$ , the social capital for unskilled individuals will scale down in Figure 1.

It scales down because of the condition:

$w_{s}>w_{u}$ Therefore: $\left(\frac{w_{u}}{w_{s}}\right)^{\alpha+\beta}<1$

\footnotetext{
${ }^{7}$ For detailed working of graph, see Appendix E \& F
} 


\section{Zero Bequest Level}

When an individual must finance the entire cost of education, we can determine whose social capital will be higher, by comparing those who borrow money to become skilled to those who prefer to remain unskilled. To make this comparison simpler, we find a threshold level of non-monetary cost of social exclusion. An individual who has a non-monetary cost below this threshold will have a higher social capital by remaining unskilled versus that individual who borrows money to become skilled. If the non-monetary cost crosses this threshold level, all individuals who borrow money to become skilled will have a higher social capital compared to those who prefer to remain unskilled. Thus, this condition is found by comparing:

$$
\begin{aligned}
& S^{*}(\mathrm{~b}=0) \leq \operatorname{Sun}(\mathrm{b}=0)\left(\frac{w_{u}}{w_{s}}\right)^{\alpha+\beta} \\
& \frac{(1-\alpha-\beta)\left[(-h)\left\{\beta_{m}(1+r)-w s\right\}+w s \beta_{m}\right]}{(-h)\left[(1-\alpha-\beta) \beta_{n m}-\gamma w_{s}\right]+\gamma w s \beta_{m}} \leq \frac{(1-\alpha-\beta)\left[b(1+r)+w_{u}(2+r)\right]}{\gamma w_{u}}\left(\frac{w_{u}}{w_{s}}\right)^{\alpha+\beta} \\
& \beta_{n m} \leq \frac{2+r\left[\gamma w s\left(h+\beta_{m}\right]-\left(\frac{w_{s}}{w_{u}}\right)^{\alpha+\beta} \gamma\left[-h\left\{\beta_{m}(1+r)-w s\right\}+w s \beta_{m}\right]\right.}{(h)(2+r)(1-\alpha-\beta)}
\end{aligned}
$$

Therefore, as long as $\beta_{n m} \leq \overline{\beta_{n m}}=\mathrm{S}^{*}(\mathrm{~b}=0)<\mathrm{Sun}(\mathrm{b}=0)\left(\frac{w_{u}}{w_{s}}\right)^{\alpha+\beta}$

\section{Bequest Dynamics}

The evolution of bequest is determined by the following sequence: ${ }^{8}$

For an unskilled individual:

$\mathrm{b}_{\mathrm{t}+1}=\beta \log \left[\mathrm{b}(1+\mathrm{r})+\mathrm{w}_{\mathrm{u}}(2+\mathrm{r})\right] \quad$ if $0 \leq b_{t} \leq f$

For skilled borrowers:

$\beta \log \left[(\mathrm{b}-\mathrm{h})(1+\mathrm{i})+\mathrm{w}_{\mathrm{s}}\right] \quad$ if $f \leq b_{t} \leq h$

For skilled individual:

$$
\beta \log \left[\mathrm{b}(1+\mathrm{r})+\mathrm{w}_{\mathrm{s}}\right] \quad \text { if } \mathrm{h} \leq b_{t}
$$

\footnotetext{
${ }^{8}$ For detailed working, see Appendix G
} 
Such that the long-run equilibrium for all three classes are shown in figure 2 .

\section{Figure 2}

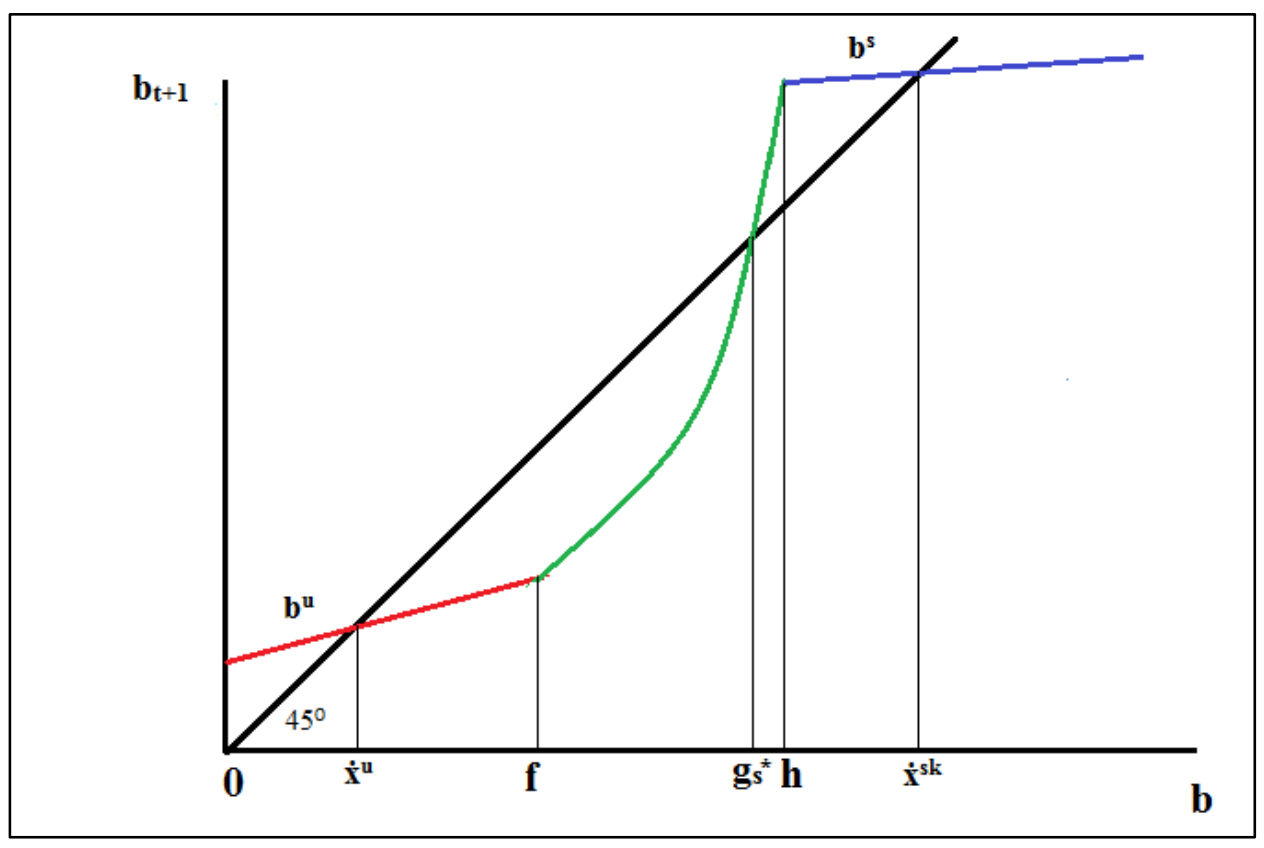

From Figure 2, we can see that individuals who inherit a bequest that is less than $f$ remain unskilled throughout their lives as will their children. In the long-run, their bequest converges to the level, $\dot{\mathrm{x}}^{\mathrm{u}}$ :

$$
\mathrm{b}=\frac{\beta[w u(2+r)]}{1-\beta b(1+r)}=\mathrm{b}^{\mathrm{u}} \text { or } \dot{\mathrm{x}}^{\mathrm{u}}
$$

Those who inherit a bequest level more than $f$, invest in social capital and receive a reduced interest rate on borrowed money in order to accumulate costly education. Their descendants may or may not become skilled as it depends on the critical point, $g_{s}{ }^{*}$.

$$
b=\beta\left(S^{*}\right)
$$

Individuals who inherit less than this critical point initially invest in human capital, but their future generations may be unable to become skilled, and converge to an unskilled long-run equilibrium, $\dot{x}^{u}$. For those who inherit more than this critical point, their descendants are able to become skilled and converge to the skilled long-run equilibrium level, $\dot{x}^{\text {sk}}$ : 


$$
\mathrm{b}=\frac{\beta[w s-h(1+r)]}{1-\beta b(1+r)}=\mathrm{b}^{\mathrm{s}} \text { or } \dot{\mathrm{x}}^{\mathrm{sk}}
$$

\section{Proposition 2}

If an economy fulfills the condition where $0<g_{s}{ }^{*}<\dot{\mathbf{X}}^{\text {sk }}$ then its composition of skilled and unskilled laborers depends on the number of individuals who inherit less than $g_{s}{ }^{*}$ in time period, $t$.

This proposition highlights a critical point, $g_{s}{ }^{*}$, upon which the dynamics of the economy are dependent. In Figures 1 and 2, this critical point occurs between threshold $f$ and $h$. In an economy with initially poor conditions and low bequest levels, individuals prefer to remain unskilled in both time periods 1 and 2. For this group, investment in human capital is not a preference since utility for being skilled is less than utility for being unskilled. This economy converges to the long-run equilibrium of unskilled individuals at $\dot{\mathrm{x}}^{u}$ as proved in equation (16).

In an economy which inherits greater bequest than the critical point, $g_{s}{ }^{*}$, utility for being skilled is greater than that for being unskilled. There are two further categories: 1) those who can cover the costly human capital and have additional funds to lend and earn a return, and 2) those who still invest in social capital accumulation and acquire loans at an interest rate, i, which is lower than the market interest rate to invest in human capital accumulation. The latter group is able to earn skilled labor wages in the future to cover the critical point, $g_{s}{ }^{*}$, in order to converge to the long-run equilibrium of skilled individuals, $\dot{x}^{s k}$.

From Figure 2, we can see that the threshold $f$ and $g_{s}{ }^{*}$ are the critical thresholds for short-run and long-run, respectively. Thus, we perform a comparative static analysis to see if these thresholds can be reduced to zero.

\section{Proposition 3}

$$
\frac{\partial f}{\partial \beta_{n m}} \text { is positive } \frac{\partial g s *}{\partial \beta_{n m}} \text { is negative }{ }^{9}
$$

This comparative static shows that in the short-run, a higher nonmonetary cost is going to increase the threshold, $f$. This implies that fewer people are initially aware of the benefits of social capital. On the contrary, in the long-run, a higher non-monetary cost decreases the threshold, $g_{s}{ }^{*}$. This implies that due to the benefit of better information, more people are

\footnotetext{
${ }^{9}$ For detailed working, see Appendix H
} 
going to become skilled by borrowing at lower-than-market interest rates, as will their future descendants. However, as stated earlier, those who inherit more than $g_{s}{ }^{*}$ converge to a higher long-run equilibrium, $\dot{X}^{\text {sk, }}$, where all individuals are skilled.

\section{Conclusion}

The results of our model show that various inherited bequest levels will influence individuals to make optimal decisions to a) invest in social capital and, b) to borrow money. An inherited bequest below the costly human capital implies that such individuals decide that it is not optimal not to borrow money or invest in education. An individual with an inherited bequest below the level of costly education, but higher than what unskilled individuals inherit, find it optimal to borrow money to become skilled. They are charged a lower-than-market interest rate if they continue to invest in social capital. A third category of individuals can finance their entire education without borrowing; this group becomes the lenders of the society.

This paper comes to a different conclusion than that of Galor and Zeira (1993). They concluded that the distribution of skilled and unskilled labor is solely dependent upon the individual's initial inheritance level, which also determines the aggregate output and macroeconomic equilibrium in the long-run. Those who inherit more than the critical threshold will converge to a higher long-run equilibrium. Thus, if all individuals converge to the same long-run equilibrium, then the future descendants will know their bequest level. On the other hand, our paper's focus is on the psychological cost of social exclusion from mobility, and that skilled wages can create a difference in the long-run equilibria. Also, those who require additional funds to finance their education can do so by investing in social capital and receiving a reduced interest rate on their loans. The wealth distribution have implications in the short-run and long-run.

The long-run policy of subsidized education has a negative effect due to several factors. In economics, the price of a product, in this case, education, is derived from the interaction of supply and demand. When its value is artificially reduced by government policy, it creates a shortage where many parents want to enroll their children in school but the supply of teachers is comparatively low. In this way, only select students can enroll. Also, employee satisfaction is reduced as their job is no longer performance-based and the education standards drop. Other problems include interest rate caps on loans where marginalized groups in society or those with fewer political connections are unable to receive reduced-rate loans to finance their children's education. 
All governments are endowed with limited resources and efficient allocation of those resources is important. Long-run government policies to promote social capital should aim to provide participatory and inclusive projects. This does not mean that similar policies can be applied across all nations since the benefits of social capital are localized. Government can promote volunteer work, network building, or participation in community-building programs with promised rewards. Government also could discourage the negative externalities that arise from wrongful use of social capital by certain influential groups of the society. Special interest groups can also exploit the community when they invest in the social capital within their network. Lastly, governments can spend resources on advertising where networking benefits are heavily focused. Social capital comes as a complementary feature when policies are designed towards it. Well-connected individuals are better employed, housed, and are ultimately more content and satisfied with their surroundings. The welfare effects of health, once internalized, leads to higher long-run aggregate output. Also, the government itself can invest in developing trust by ensuring property rights and not expropriating individual's assets. 


\section{References}

Becker, G. S. (1994). Human capital revisited. In Human Capital: A Theoretical and Empirical Analysis with Special Reference to Education (3rd Edition), pp. 15-28. The University of Chicago press

Becker, G. S., \& Mulligan, C. B. (1997). The endogenous determination of time preference. The Quarterly Journal of Economics, 112(3), 729-758. Bureau of Economic Research.

Chou, Y. K. (2006). Three simple models of social capital and economic growth. The Journal of Socio-Economics, 35(5), 889-912.

Chou, Y. K. (2006). Three simple models of social capital and economic growth. The Journal of Socio-Economics, 35(5), 889-912.

Coleman, J. S. (1988). Social capital in the creation of human capital. American Journal of Sociology, 94, S95-S120.

Coleman, J. S. (1994). Foundations of Social Theory. Harvard University Press.

Dasgupta, P., \& Mäler, K. G. (1995). Poverty, institutions, and the environmental resource-base. Handbook of Development Economics, 3, 2371-2463.

Dincer, O. C., \& Uslaner, E. M. (2010). Trust and growth. Public Choice, 142(1-2), 59.

Dinda, S. (2008). Social capital in the creation of human capital and economic growth: A productive consumption approach. Journal of Socio-Economics, 37(5), 2020-2033.

Duffhues, P., \& Weterings, W. (2011). The quality of credit ratings and liability: The Dutch view. International Journal of Disclosure and Governance, 8(4), 339-359.

Galor, O., \& Zeira, J. (1993). Income distribution and macroeconomics. The Review of Economic Studies, 60(1), 35-52.

Glaeser, E. L., Laibson, D., \& Sacerdote, B. (2002). An economic approach to social capital. The Economic Journal, 112(483), F437-F458. 
Helliwell, J. F., \& Putnam, R. D. (1995). Economic growth and social capital in Italy. Eastern Economic Journal, 21(3), 295-307.

Imandoust, S. B. (2011). Relationship between education and social capital. International Journal of Humanities and Social Science, 1(12), 52-57.

Kawachi, I., Kennedy, B. P., Lochner, K., \& Prothrow-Stith, D. (1997). Social capital, income inequality, and mortality. American Journal of Public Health, 87(9), 1491-1498.

Knack, S., \& Keefer, P. (1997). Does social capital have an economic payoff? A cross-country investigation. The Quarterly Journal of Economics, 112(4), 1251-1288.

La Porta, R., Lopez-de-Silanes, F., Shleifer, A., \& Vishny, R. (1999). The quality of government. The Journal of Law, Economics, and Organization, 15(1), 222-279.

Leana III, C. R., \& Van Buren, H. J. (1999). Organizational social capital and employment practices. Academy of Management Review, 24(3), 538555.

Lin, N. (2000). Inequality in social capital. Contemporary Sociology, 29(6), 785-795.

Lucas, R.E (1988). On the Mechanics of Economic Development. Journal of Monetary Economics 22, 3-42.

Mare, R. D. (1991). Five decades of educational assortative mating. American Sociological Review, 15-32.

Nelson, R. R., \& Phelps, E.S. (1966). Investment in humans, technological diffusion, and economic growth. American Economic Review 56(1/2),69-75.

Putnam, R. D. (1995). Bowling alone: America's declining social capital. Journal of Democracy, 6(1), 65-78.

Putnam, R. D. (2000). Bowling alone: America's declining social capital. In Culture and Politics, pp. 223-234. Palgrave Macmillan, New York. 
Romer, P. M. (1989). Human capital and growth: Theory and evidence, No. w3173, National Bureau of Economic Research.

Spence, M. (1973). Job market signaling. The Quarterly Journal of Economics, 355-374.

Stiglitz, J. E. (1990). Peer monitoring and credit markets. The World Bank Economic Review, 4(3), 351-366.

Van Staveren, I., \& Knorringa, P. (2007). Unpacking social capital in economic development: How social relations matter. Review of Social Economy, 65(1), 107-135. 


\section{Appendix}

\section{Appendix A}

In this appendix, we give a detailed exposition of the Lagrangian calculations and the optimal values of different components.

$$
\underset{c, b, S_{i}}{\operatorname{Max}} U_{i, t+1}=\alpha \log \left(c_{t+1}\right)+\beta \log \left(b_{t+1}\right)+(1-\alpha-\beta) \log R(\hat{S}) \cdot S_{i, t+1}
$$

subject to:

$$
y_{t+1}=c_{t+1}+b_{t+1}+\gamma_{i} S_{t+1}
$$

By setting up the Lagrange, we derive the following expressions: $\left.\gamma_{i} S_{t+1}\right]$

$$
L=\alpha \log \left(c_{t+1}\right)+\beta \log \left(b_{t+1}\right)+(1-\alpha-\beta) \log R(\hat{S}) \cdot S_{i, t+1}+\lambda\left[y_{t+1}-c_{t+1}+b_{t+1}+\right.
$$

$$
\begin{aligned}
& \frac{\partial L}{\partial c}=\frac{\alpha}{c_{t+1}}=\lambda \\
& \frac{\partial L}{\partial b}=\frac{\beta}{b_{t+1}}=\lambda \\
& \frac{\partial L}{\partial S}=\frac{1-\alpha-\beta}{S_{t+1}}=\lambda \\
& \frac{\partial L}{\partial \lambda}=y_{t+1}=c_{t+1}+b_{t+1}+\gamma_{i} S_{t+1}
\end{aligned}
$$

By using equation (i) $\mathcal{E}$ (iii), we find:

$$
c_{t+1}=\frac{\alpha \gamma_{i} S t+1}{1-\alpha-\beta}
$$

By using equation (ii) $\mathcal{E}$ (iv), we find:

$$
b_{t+1}=\frac{\beta \gamma_{i} S t+1}{1-\alpha-\beta}
$$

Applying $(A) \mathcal{E}(B)$ to equation (iv), we get:

$$
\begin{aligned}
& y=\frac{\alpha \gamma_{i} S t+1}{1-\alpha-\beta}+\frac{\beta \gamma_{i} S t+1}{1-\alpha-\beta}+\gamma_{i} S_{t+1} \\
& S_{t+1}{ }^{*}=\frac{(1-\alpha-\beta) y_{t+1}}{\gamma_{i}}
\end{aligned}
$$


Applying to $(A)$ and $(B)$ to find $c^{*}$ and $b^{*}$

$$
\begin{aligned}
& c_{t+1}{ }^{*}=\alpha y_{t+1} \\
& b_{t+1}{ }^{*}=\beta y_{t+1}
\end{aligned}
$$

The indirect utility function is calculated as:

$$
\mathrm{V}=\alpha \log \left(c_{t+1}\right)+\beta \log \left(b_{t+1}\right)+(1-\alpha-\beta) \log R(\hat{S}) \cdot S_{i, t+1}
$$

Apply the optimal values for consumption, bequest and social capital in the function above to find the indirect utility function.

$$
\begin{gathered}
\mathrm{V}=\alpha \log \left(\alpha y_{t+1}\right)+\beta \log \left(\beta y_{t+1}\right)+(1-\alpha-\beta) \log R(\hat{S}) \cdot \frac{(1-\alpha-\beta) y_{t+1}}{\gamma} \\
\mathrm{V}=\alpha \log (\alpha)+\alpha \log \left(y_{t+1}\right)+\beta \log (\beta)+\beta \log \left(y_{t+1}\right)+(1-\alpha-\beta) \log R(\hat{S})+(1- \\
\alpha-\beta) \log (1-\alpha-\beta)+(1-\alpha-\beta) \log y_{t+1}-(1-\alpha-\beta) \log \gamma
\end{gathered}
$$

Simplifying the expression, we get:

$$
\begin{aligned}
& V_{t}=\log y_{t+1}-(1-\alpha-\beta) \log \gamma_{i}+\varepsilon \\
& \varepsilon=\alpha \log \alpha+\beta \log \beta+(1-\alpha-\beta) \log (1-\alpha-\beta)+(1-\alpha-\beta) \log R(\hat{S})
\end{aligned}
$$




\section{Appendix B}

In this appendix, we solve for the incentive compatibility constraint where an individual is indifferent between the default amount or incurring monitoring as well as non-monitoring cost.

$$
d(1+i)=\beta_{m .} . z f\left(S_{i}\right)+\beta_{n m} f\left(S_{i}\right)
$$

Making ' $z$ ' the subject of the equation, we get:

capital)

$$
z f\left(S_{i}\right)=\frac{d(1+i)-\beta_{n m} f(S i)}{\beta_{m}} \quad\left(\mathrm{z} \text { and } \beta_{\mathrm{nm}}\right. \text { are linear functions of social }
$$

Applying to the equation below, which shows per unit cost of interest rate which the lender charges:

$$
\begin{aligned}
& i=r+z f\left(S_{i}\right) \\
& i=r+\frac{d(1+i)-\beta_{n m} f(S i)}{\beta_{m}} \\
& i \beta_{m}=r \beta_{m}-\beta_{n m}(S i)+d(1+i) \\
& i \beta_{m}-d i=r \beta_{m}-\beta_{n m}(S i)+d \\
& i=\frac{r \beta_{m}+d-\beta_{n m} f(S i)}{\left(\beta_{m}-d\right)} \\
& 1+i=\frac{\beta_{m}[1+r]-\beta_{n m} f(S i)}{\left(\beta_{m}-d\right)}
\end{aligned}
$$

Note: $\mathrm{d}=(\mathrm{b}-\mathrm{h})$ is negative since this is the amount borrowed.

$\beta_{n m}=f\left(S_{i}\right) \quad$ (linear function)

Now, we will perform the comparative static analysis on $(1+i)$ with respect to non-monetary cost of social capital

$$
\frac{\partial(1+i)}{\partial S_{i}}=\frac{-\left(\beta_{n m}\right)}{\left(\beta_{m}-d\right)}<0
$$

Since, (b-h) is negative, the derivative becomes negative. This relationship implies that as the social capital accumulation of an individual increases, the interest charged on the amount borrowed decreases. 


\section{Appendix C}

In this appendix, we find the solution to the assumption that was used in the paper.

Assumption 1 proves whether an individual invests in human capital or not. For this we compare the indirect utility of being skilled $(b>h)$ with that of being unskilled $(b<h)$.

$$
\begin{aligned}
& \mathrm{V}_{\mathrm{s}} \geq \mathrm{V}_{\mathrm{u}} \\
& \log \left[\left(b_{t}-h\right)(1+r)+w_{s}\right]+\log (1-\alpha-\beta) \log R(\hat{S})-(1-\alpha-\beta) \log \gamma w_{s} \quad \geq \\
& \log \left[b_{t}(1+r)+w_{u}(2+r)\right]+(1-\alpha-\beta) \log R(\hat{S})-(1-\alpha-\beta) \log \gamma w_{u}
\end{aligned}
$$

By taking the anti-log, we find:

$$
\begin{aligned}
& {\left[\left(b_{t}-h\right)(1+r)+w_{s}\right] \geq\left(\frac{w_{s}}{w_{u}}\right)^{1-\alpha-\beta}\left[b(1+r)+w_{u}(2+r)\right]} \\
& \frac{(b-h)(1+r)+w_{s}}{b(1+r)+w_{u}(2+r)} \geq\left(\frac{w_{s}}{w_{u}}\right)^{1-\alpha-\beta}
\end{aligned}
$$

The ratio of a skilled individual's income to an unskilled individual's income is greater than the ratio of their wage rates. If this binding condition is satisfied, an individual invests in human capital. 


\section{Appendix D}

The second condition shows if an individual invests in social capital or not. For this we compare the indirect utility of being skilled by borrowing $(b<h)(1+i)$ with that of an unskilled individual $(b<h)$.

Finding threshold $f$ from the condition:

$$
\begin{aligned}
& \mathrm{V}_{\mathrm{s}}^{*} \geq \mathrm{V}_{\mathrm{u}} \\
& \begin{array}{l}
\log \left[\left(b_{t}-h\right)(1+i)+w_{s}\right]-(1-\alpha-\beta) \log \gamma \mathrm{w}_{\mathrm{s}} \quad \geq \log \left[b_{t}(1+r)+w_{u}(2+r)\right]- \\
\quad(1-\alpha-\beta) \log \gamma w_{u}
\end{array}
\end{aligned}
$$

By taking the anti-log, we find:

$$
\left[\left(b_{t}-h\right)(1+i)+w_{s}\right] \geq\left(\frac{w_{s}}{w_{u}}\right)^{1-\alpha-\beta}\left[b(1+r)+w_{u}(2+r)\right]
$$

Simplifying the expression, we get:

$$
S^{*} \frac{\gamma w_{S}}{(1-\alpha-\beta)} \gtreqless S^{u} \cdot \frac{\gamma w_{u}}{(1-\alpha-\beta)} \cdot\left(\frac{w_{u}}{w_{s}}\right)^{\alpha+\beta}
$$

Factoring out $\frac{\gamma}{(1-\alpha-\beta)}$

Now apply the values for $S^{*}$ and $S^{u}$ in the expressions above:

$$
\begin{aligned}
& (1-\alpha-\beta)\left[\frac{(b-h)\left\{\beta_{m}[1+r]-w_{s}\right\}+w_{s} \beta_{m}}{\left[(b-h)\left\{(1-\alpha-\beta) \beta_{n m}-\gamma w_{s}\right\}+\gamma w_{s} \beta_{m}\right]}\right] \geq \frac{(1-\alpha-\beta)}{\gamma w_{u}}\left(\frac{w_{u}}{w_{s}}\right)^{\alpha+\beta}[b(1+r)+ \\
& \left.w_{u}(2+r)\right] \\
& \gamma w_{u} \cdot\left[(b-h)\left\{\beta_{m}[1+r]-w_{s}\right\}+w_{s} \beta_{m}\right] \geq[(b-h)\{(1-\alpha- \\
& \left.\left.\beta) \beta_{n m}-\gamma w_{s}\right\}+\gamma w_{s} \beta_{m}\right] \cdot\left(\frac{w_{u}}{w_{s}}\right)^{\alpha+\beta}\left[b(1+r)+w_{u}(2+r)\right] \\
& \left.\gamma w_{u} \cdot\left[(b-h)\left\{\beta_{m}(1+r)-w_{s}\right\}\right]+\gamma w_{u} w_{s} \beta_{m}\right] \geq \\
& \left(\frac{w_{u}}{w_{s}}\right)^{\alpha+\beta}[b(1+r)] .\left[(b-h)\left\{(1-\alpha-\beta) \beta_{n m}-\gamma w_{s}\right\}+\gamma w_{s} \beta_{m}\right] .+ \\
& \left(\frac{w_{u}}{w_{s}}\right)^{\alpha+\beta} \cdot w_{u}(2+r)\left[(b-h)\left\{(1-\alpha-\beta) \beta_{n m}-\gamma w_{s}\right\}+\gamma w_{s} \beta_{m}\right]
\end{aligned}
$$

Note: We assume: $\gamma w_{s}>(1-\alpha-\beta) \beta_{n m}$ throughout our analysis:

$$
b^{2}(1+r)\left(\frac{w_{u}}{w_{s}}\right)^{\alpha+\beta}\left\{\gamma w_{s}-(1-\alpha-\beta) \beta_{n m}\right\}
$$




$$
\begin{aligned}
&+b\left[\gamma w_{u}\right.\left\{\beta_{m}(1+r)-w_{s}\right\}-h(1+r)\left(\frac{w_{u}}{w_{s}}\right)^{\alpha+\beta}\left\{\gamma w_{s}-(1-\alpha-\right. \\
&\left.\beta) \beta_{n m}\right\}-(1+r)\left(\frac{w_{u}}{w_{s}}\right)^{\alpha+\beta} \gamma w_{s} \beta_{m}+w u(2+r)\left(\frac{w_{u}}{w_{s}}\right)^{\alpha+\beta}\left\{\gamma w_{s}-\right. \\
&\left.\left.(1-\alpha-\beta) \beta_{n m}\right\}\right] \\
&+\left[-\gamma w_{u} \cdot h\left\{\beta_{m}(1+r)-w_{s}\right\}+\gamma w_{u} w_{s} \beta_{m}-w u(2+r) h\left(\frac{w_{u}}{w_{s}}\right)^{\alpha+\beta}\left\{\gamma w_{s}-\right.\right. \\
&\left.\left.(1-\alpha-\beta) \beta_{n m}\right\}-w u(2+r)\left(\frac{w_{u}}{w_{s}}\right)^{\alpha+\beta} \gamma w_{s} \beta_{m}\right]
\end{aligned}
$$

Checking if the positive/negative root is $\gtreqless h$

$$
\begin{aligned}
& f_{\text {positive }} \gtreqless h \\
& \frac{-b+\sqrt{b^{2}-4 a c}}{2 a} \gtreqless h \\
& f_{\text {positive }} \gtreqless h \\
& \frac{-b+\sqrt{b^{2}-4 a c}}{2 a} \gtreqless h \\
& b^{2}-4 a c \gtreqless(2 a h+b)^{2} \\
& b^{2}-4 a c \gtreqless\left(4 a^{2} h^{2}+b^{2}+4 a h b\right) \\
& -c \gtreqless a h^{2}+b h \\
& -\left[-\gamma w_{u} \cdot h\left\{\beta_{m}(1+r)-w_{s}\right\}+\gamma w_{u} w_{s} \beta_{m}-w u(2+r) h\left(\frac{w_{u}}{w_{s}}\right)^{\alpha+\beta}\left\{\gamma w_{s}-\right.\right. \\
& \left.\left.\quad(1-\alpha-\beta) \beta_{n m}\right\}-w u(2+r)\left(\frac{w_{u}}{w_{s}}\right)^{\alpha+\beta} \gamma w_{s} \beta_{m}\right]
\end{aligned}
$$

Factoring out $\gamma w_{s} \beta_{m}$ :

$$
w_{u}\left[(2+r)\left(\frac{w_{u}}{w_{s}}\right)^{\alpha+\beta}-1\right] \gtreqless-h(1+r)\left(\frac{w_{u}}{w_{s}}\right)^{\alpha+\beta}
$$


Since, L.H.S > R.H.S, the positive root $>h$

$$
\begin{aligned}
& f_{\text {negative }} \gtreqless h \\
& \frac{-b-\sqrt{b^{2}-4 a c}}{2 a} \gtreqless h \\
& -b^{2}+4 a c \gtreqless(2 a h+b)^{2} \\
& -b^{2}+4 a c \gtreqless\left(4 a^{2} h^{2}+b^{2}+4 a h b\right) \\
& 2 a c \gtreqless 2 a^{2} h^{2}+b^{2}+2 a h b
\end{aligned}
$$

Applying the values:

$$
\begin{aligned}
& 2(1+r)\left(\frac{w_{u}}{w_{s}}\right)^{\alpha+\beta}\left\{\gamma w_{s}-(1-\alpha-\beta) \beta_{n m}\right\}\left[-\gamma w_{u} \cdot h\left\{\beta_{m}(1+r)-w_{s}\right\}+\right. \\
& \gamma w_{u} w_{s} \beta_{m}-w u(2+r) h\left(\frac{w_{u}}{w_{s}}\right)^{\alpha+\beta}\left\{\gamma w_{s}-(1-\alpha-\beta) \beta_{n m}\right\}- \\
& \left.w u(2+r)\left(\frac{w_{u}}{w_{s}}\right)^{\alpha+\beta} \gamma w_{s} \beta_{m}\right] \gtreqless \\
& h^{2}(1+r)^{2}\left(\frac{w_{u}}{w_{s}}\right)^{\alpha+\beta^{2}}\left\{\gamma w_{s}-(1-\alpha-\beta) \beta_{n m}\right\}^{2}+\gamma^{2} w_{u}{ }^{2}\left\{\beta_{m}(1+\right. \\
& \left.r)-w_{s}\right\}^{2} \\
& +h^{2}(1+r)^{2}\left(\frac{w_{u}}{w_{s}}\right)^{\alpha+\beta^{2}}\left\{\gamma w_{s}-(1-\alpha-\beta) \beta_{n m}\right\}^{2}+(1+ \\
& r)^{2}\left(\frac{w_{u}}{w_{s}}\right)^{\alpha+\beta^{2}} \gamma^{2} w_{s}{ }^{2} \beta_{m}^{2} \\
& +w_{u}^{2}(2+r)^{2}\left(\frac{w_{u}}{w_{s}}\right)^{\alpha+\beta^{2}}-2 \gamma w_{u}\left\{\beta_{m}(1+r)-w_{s}\right\} \cdot h(1+ \\
& r)\left(\frac{w_{u}}{w_{s}}\right)^{\alpha+\beta}\left\{\gamma w_{s}-(1-\alpha-\beta) \beta_{n m}\right\}-2 \gamma^{2} w_{u}\left\{\beta_{m}(1+r)-\right. \\
& \left.w_{s}\right\} \cdot\left\{(1+r)\left(\frac{w_{u}}{w_{s}}\right)^{\alpha+\beta^{2}} w_{s} \beta_{m}\right\}+2 \gamma w_{u}{ }^{2}(2+r)\left\{\beta_{m}(1+r)-\right. \\
& \left.w_{s}\right\} \cdot\left(\frac{w_{u}}{w_{s}}\right)^{\alpha+\beta}\left\{\gamma w_{s}-(1-\alpha-\beta) \beta_{n m}\right\}+2 h(1+ \\
& r)^{2}\left(\frac{w_{u}}{w_{s}}\right)^{\alpha+\beta^{2}} \gamma w_{s} \beta_{m} \cdot\left\{\gamma w_{s}-(1-\alpha-\beta) \beta_{n m}\right\}-2 h(1+ \\
& r)\left(\frac{w_{u}}{w_{s}}\right)^{\alpha+\beta^{2}} \cdot w u(2+r) \cdot\left\{\gamma w_{s}-(1-\alpha-\beta) \beta_{n m}\right\}^{2}- \\
& 2\left(\frac{w_{u}}{w_{s}}\right)^{\alpha+\beta^{2}}(1+r) \cdot w u(2+r) \cdot \gamma w_{s} \beta_{m} \cdot\left\{\gamma w_{s}-(1-\alpha-\right. \\
& \left.\beta) \beta_{n m}\right\}^{2}
\end{aligned}
$$




$$
\begin{aligned}
+2(1+r)\left(\frac{w_{u}}{w_{s}}\right)^{\alpha+\beta}\left\{\gamma w_{s}-(1-\alpha-\beta) \beta_{n m}\right\} h \gamma w_{u}\left\{\beta_{m}(1+r)-w_{s}\right\}- \\
2 h^{2}(1+r)^{2}\left(\frac{w_{u}}{w_{s}}\right)^{\alpha+\beta^{2}}\left\{\gamma w_{s}-(1-\alpha-\beta) \beta_{n m}\right\}^{2}- \\
2(1+r)^{2}\left(\frac{w_{u}}{w_{s}}\right)^{\alpha+\beta^{2}} \cdot \gamma w_{s} \beta_{m} \cdot\left\{\gamma w_{s}-(1-\alpha-\beta) \beta_{n m}\right\}+2(1+ \\
r) h\left(\frac{w_{u}}{w_{s}}\right)^{\alpha+\beta^{2}} w u(2+r)\left\{\gamma w_{s}-(1-\alpha-\beta) \beta_{n m}\right\}^{2}
\end{aligned}
$$

Solving the expression, we get:

Therefore,

$$
\begin{aligned}
& 2(1+r)\left(\frac{w_{u}}{w_{s}}\right)^{\alpha+\beta}\left\{\gamma w_{s}-(1-\alpha-\beta) \beta_{n m}\right\} \gamma w_{u} w_{s} \beta_{m}\left[1-2\left(\frac{w_{u}}{w_{s}}\right)^{\alpha+\beta}\right] \\
& \gtreqless \\
& 2 h^{2}(1+r)^{2}\left(\frac{w_{u}}{w_{s}}\right)^{\alpha+\beta^{2}}\left\{\gamma w_{s}-(1-\alpha-\beta) \beta_{n m}\right\}^{2}+\gamma^{2} w_{u}^{2}\left\{\beta_{m}(1+\right. \\
& \left.r)-w_{s}\right\}^{2}(1+r)^{2}\left(\frac{w_{u}}{w_{s}}\right)^{\alpha+\beta^{2}} \gamma^{2} w_{s}^{2} \beta_{m}^{2}+w_{u}^{2}(2+ \\
& r)^{2}\left(\frac{w_{u}}{w_{s}}\right)^{\alpha+\beta^{2}}+2 \gamma w_{u}^{2}(2+r)\left\{\beta_{m}(1+r)-\right. \\
& \left.w_{s}\right\} \cdot\left(\frac{w_{u}}{w_{s}}\right)^{\alpha+\beta}\left\{\gamma w_{s}-(1-\alpha-\beta) \beta_{n m}\right\}-2 \gamma^{2} w_{u}\left\{\beta_{m}(1+r)-\right. \\
& \left.w_{s}\right\} \cdot\left\{(1+r)\left(\frac{w_{u}}{w_{s}}\right)^{\alpha+\beta^{2}} w_{s} \beta_{m}\right\}+2(1+r)\left(\frac{w_{u}}{w_{s}}\right)^{\alpha+\beta}\left\{\gamma w_{s}-\right. \\
& \left.(1-\alpha-\beta) \beta_{n m}\right\} h \gamma w_{u}\left\{\beta_{m}(1+r)-w_{s}\right\} \\
& -2\left(\frac{w_{u}}{w_{s}}\right)^{\alpha+\beta^{2}}(1+r) \cdot w u(2+r) \cdot \gamma w_{s} \beta_{m} \cdot\left\{\gamma w_{s}-(1-\alpha-\right. \\
& \left.\beta) \beta_{n m}\right\}^{2}+2(1+r) h\left(\frac{w_{u}}{w_{s}}\right)^{\alpha+\beta^{2}} w u(2+r)\left\{\gamma w_{s}-\right. \\
& \left.(1-\alpha-\beta) \beta_{n m}\right\}^{2}
\end{aligned}
$$

L.H.S is negative due to the term $1<2\left(\frac{w_{u}}{w_{s}}\right)^{\alpha+\beta}$ and R.H.S is positive.

Therefore, $f_{\text {negative }}<h$

This threshold depicts that whoever inherits a bequest level beyond $f$ finds it optimal to invest in social capital irrespective of their occupation. 


\section{Appendix E}

In this appendix, we find the optimal investment in social capital given the individuals borrow money. Since interest rate is a function of social capital and the general form of social capital is a function of interest rate, we will solve them simultaneously.

$$
\begin{aligned}
& 1+i=\frac{\beta_{m}[1+r]-\beta_{n m} \cdot S i}{d\left(\beta_{m}-1\right)} \\
& S=\frac{(1-\alpha-\beta)[(b-h)(1+i)+w s]}{\gamma w_{s}}
\end{aligned}
$$

By applying the value for $(1+i)$ in the equation for optimal investment in social capital, we find $S^{*}$ :

$$
\begin{aligned}
& S=\frac{(1-\alpha-\beta)\left[(b-h)\left(\frac{\beta_{m}[1+r]-\beta_{n m} \cdot S i}{(b-h)\left(\beta_{m}-1\right)}\right)+w s\right]}{\gamma w_{s}} \\
& S^{*}=\frac{(1-\alpha-\beta)\left[(b-h)\left\{\beta_{m}(1+r)-w s\right\}+w s \beta_{m}\right]}{-(b-h)\left[\gamma w_{s}-(1-\alpha-\beta)\right]+\gamma w_{s} \beta_{m}} \\
& \beta_{n m}=S i \quad \text { (linear function) }
\end{aligned}
$$

Note: We assume $\gamma w_{s}>(1-\alpha-\beta)$ and $\mathrm{b}<\mathrm{h}$ in this case

To check the functional form of $S^{*}$, we find the first and second derivative.

$$
\begin{gathered}
\frac{\partial S^{*}}{\partial b}=\frac{\left[-(b-h)\left\{\gamma w_{s}-(1-\alpha-\beta) \beta_{n m}\right\}+\gamma w_{s} \beta_{m}\right] \cdot\left\{\beta_{m}(1+r)-w s\right\} .(1-\alpha-\beta)-\left[(1-\alpha-\beta)\left[(b-h)\left\{\beta_{m}(1+r)-w s\right\}+w s \beta_{m}\right] \ldots\right.}{\left[-(b-h)\left\{\gamma w_{s}-(1-\alpha-\beta)\right\}+\gamma w_{s} \beta_{n m}\right]^{2}} \\
\frac{\left[.-(b-h)\left\{\gamma w_{s}-(1-\alpha-\beta)\right\}\right.}{\left[-(b-h)\left\{\gamma w_{s}-(1-\alpha-\beta)\right\}+\gamma w_{s} \beta_{n m}\right]^{2}}
\end{gathered}
$$

Checking numerator for the sign:

$$
\begin{aligned}
{\left[-(b-h)\left\{\gamma w_{s}\right.\right.} & \left.-(1-\alpha-\beta) \beta_{n m}\right\} \\
& \left.+\gamma w_{s} \beta_{m}\right] \cdot\left\{\beta_{m}(1+r)-w s\right\} .(1-\alpha-\beta) \\
& \gtreqless-\left[( 1 - \alpha - \beta ) \left[(b-h)\left\{\beta_{m}(1+r)-w s\right\}\right.\right. \\
& \left.+w s \beta_{m}\right](b-h)\left\{\gamma w_{s}-(1-\alpha-\beta)\right.
\end{aligned}
$$

Factoring out: $(1-\alpha-\beta)$, we get:

$$
\gamma w_{s} \beta_{m}^{2}(1+r)-\gamma w_{s}^{2} \beta_{m} \gtreqless w_{s} \beta_{m}(1-\alpha-\beta) \beta_{n m}-\gamma w_{s}^{2} \beta_{m}
$$


$\gamma \beta_{m}(1+r)>(1-\alpha-\beta) \beta_{n m} \quad$ is positive

$\frac{\partial S^{*}}{\partial b}=+\mathrm{ve}$

Keeping $\frac{\partial S^{*}}{\partial b}=0$, we get 0 . Thus, function is minimum at value of

$S^{*}=\frac{(1-\alpha-\beta)\left[(b-h)\left\{\beta_{m}(1+r)-w s\right\}+w s \beta_{m}\right]}{(b-h)\left[(1-\alpha-\beta) \beta_{n m}-\gamma w_{s}+\right]+\gamma w s \beta_{m}}$ when $b=0$

$\frac{\partial^{2} S^{*}}{\partial b^{2}}=$

Taking $\gamma \beta_{m}(1+r)>(1-\alpha-\beta) \beta_{n m} \quad$ from the first derivative as A (+ve value)

$$
\begin{gathered}
\frac{A}{\left[-(b-h)\left\{\gamma w_{s}-(1-\alpha-\beta)\right\}+\gamma w_{s} \beta_{n m}\right]^{2}} \\
A \cdot\left[-(b-h)\left\{\gamma w_{s}-(1-\alpha-\beta)\right\}+\gamma w_{s} \beta_{n m}\right]^{-2} \\
\frac{-2 A(-1)\left\{\gamma w_{s}-(1-\alpha-\beta)\left[-(b-h)\left\{\gamma w_{s}-(1-\alpha-\beta)\right\}+\gamma w_{s} \beta_{n m}\right]\right.}{\left[-(b-h)\left\{\gamma w_{s}-(1-\alpha-\beta)\right\}+\gamma w_{s} \beta_{n m}\right]^{3}}
\end{gathered}
$$

Since, $\gamma w_{s}>(1-\alpha-\beta)$ and $b<h$ so the derivative is positive

$\frac{\partial S^{*}}{\partial b}, \frac{\partial^{2} S^{*}}{\partial b^{2}}$ both are positive which implies $S^{*}$ is convex upwards. Also, there are two roots of threshold $f$. Therefore, we proved in Appendix $\mathrm{D}$ that the positive root comes after $h$ whereas the negative root is less than $h$. 


\section{Appendix F}

In this section, we find the intersection points of $S^{u}, S^{s k}, S^{*}$. Also, their slopes and intercepts in order to perform a graphical analysis.

$$
\begin{aligned}
& S^{u}=\frac{(1-\alpha-\beta)\left[b(1+r)+w_{u}(2+r)\right]}{\gamma w_{u}} \\
& S^{s k}=\frac{(1-\alpha-\beta)\left[(b-h)(1+r)+w_{S}\right]}{\gamma w_{s}} \\
& S^{*}=\frac{(1-\alpha-\beta)\left[(b-h)\left\{\beta_{m}(1+r)-w s\right\}+w s \beta_{m}\right]}{(b-h)\left[(1-\alpha-\beta) \beta_{n m}-\gamma w_{s}+\right]+\gamma w s \beta_{m}}
\end{aligned}
$$

Slopes:

$$
\begin{aligned}
& \frac{\partial S^{u}}{\partial b}=\frac{(1-\alpha-\beta)}{\gamma w_{u}}>0 \\
& \frac{\partial S^{s k}}{\partial b}=\frac{(1-\alpha-\beta)}{\gamma w_{s}}>0 \\
& \frac{\partial S^{u n}}{\partial b}=\frac{\gamma w_{s} \beta_{m}^{2}(1+r)-w_{s} \beta_{m}(1-\alpha-\beta) \beta_{n m}}{\left[-(b-h)\left\{\gamma w_{s}-(1-\alpha-\beta)\right\}+\gamma w_{s} \beta_{n m}\right]^{2}}>0 \\
& \text { Slope } S^{u} \gtreqless S^{s k} \\
& \frac{(1-\alpha-\beta)}{\gamma w_{u}} \gtreqless \frac{(1-\alpha-\beta)}{\gamma w_{s}} \\
& w_{s} \gtreqless w_{u}
\end{aligned}
$$

Therefore, Slope $S^{u}>S^{s k}$

Since skilled wages are greater than the unskilled wages. Slope of $S^{u}$ is $>S^{s k}$

Intercepts:

$$
\begin{aligned}
& S^{u}(0)=\frac{(1-\alpha-\beta)[(2+r)]}{\gamma} \\
& \text { Ssk }(0)=\frac{(1-\alpha-\beta)\left[(-h)(1+r)+w_{S}\right]}{\gamma w_{S}} \\
& \text { Intercept } S^{u} \gtreqless S^{s k}
\end{aligned}
$$




$$
\begin{aligned}
& \frac{(1-\alpha-\beta)[(2+r)]}{\gamma} \gtreqless \frac{(1-\alpha-\beta)\left[(-h)(1+r)+w_{s}\right]}{\gamma w_{s}} \\
& w_{s}(2+r) \gtreqless(-h)(1+r)+w_{s} \\
& w_{s} \gtreqless(-h)
\end{aligned}
$$

Therefore, intercept $S^{u}>S^{s k}$

$$
S^{*}(0)=\frac{(1-\alpha-\beta)\left[(-h)\left\{\beta_{m}(1+r)-w s\right\}+w s \beta_{m}\right]}{(-h)\left[(1-\alpha-\beta) \beta_{n m}-\gamma w_{s}\right]+\gamma w s \beta_{m}}
$$

This figure below is a graphical representation of three kinds of social capital of individuals.

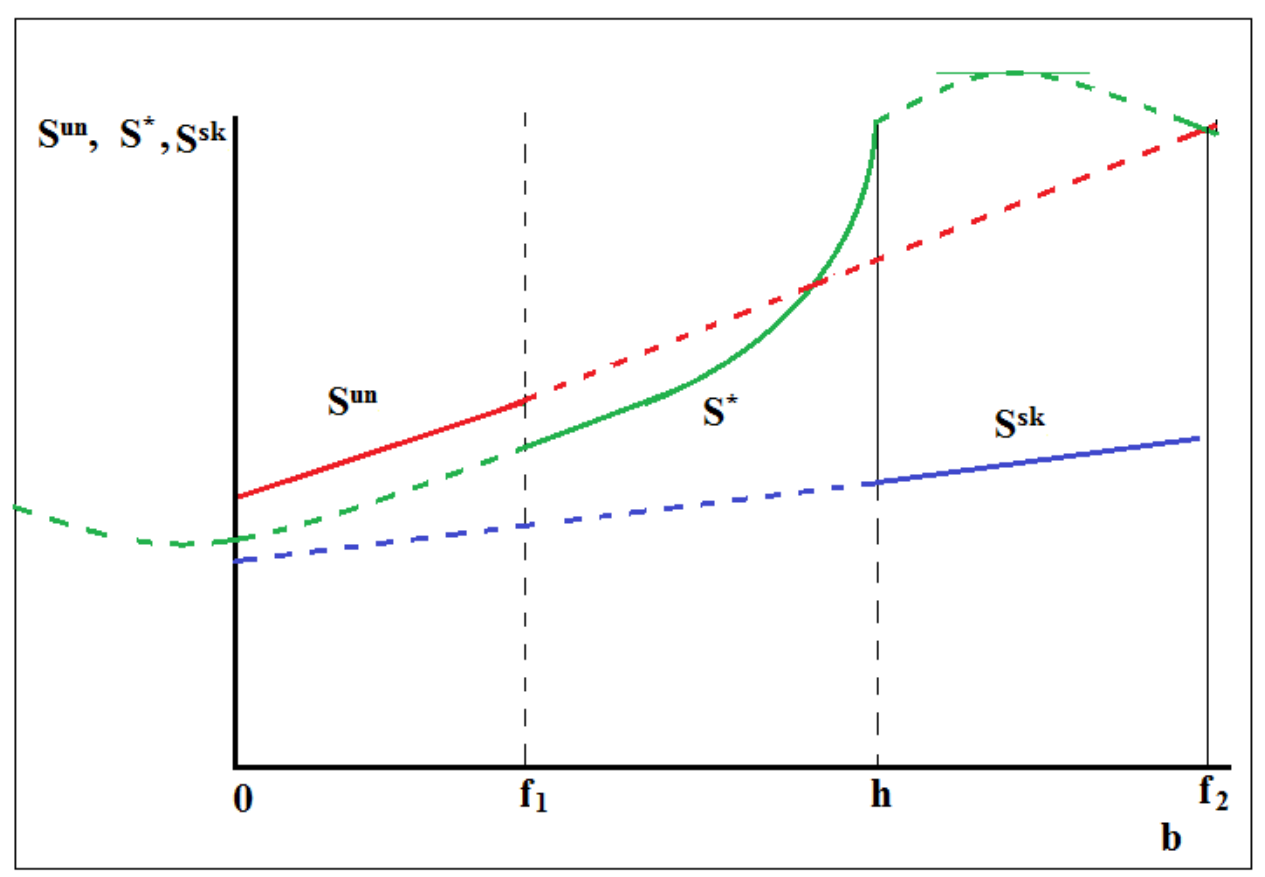

Source: Author's calculations

The first solid line shows the steeper social capital of an unskilled individual.

Since, we are using a scaler $\left(\frac{\mathrm{w}_{u}}{\mathrm{w}_{\mathrm{s}}}\right)^{\alpha+\beta}<1$ to calculate intersection of Sun and $S^{*}$; therefore, it will scale down proportionately to intersect with $S^{*}$. The second solid line is of $S^{*}$ which is convex upwards and it is point of 
inflection comes after $h$. The positive root, $f$, is greater than $h$ too. Hence, we are only considering the portion before threshold $h$. The thrid solid line is social capital of a skilled individual. Its slope is flatter than the unskilled individual's social capital. Since these individuals can afford costly education, their intersection comes after $h$ cost.

Keeping $\frac{\partial S^{*}}{\partial b}=0$, we get 0 . Thus, function is minimum at value of

$$
S^{*}=\frac{(1-\alpha-\beta)\left[(b-h)\left\{\beta_{m}(1+r)-w s\right\}+w s \beta_{m}\right]}{(b-h)\left[(1-\alpha-\beta) \beta_{n m}-\gamma w_{s}\right]+\gamma w s \beta_{m}} \text { when } \mathrm{b}=0
$$

We will now prove if $S^{*}(b=0) \gtreqless S$ un $(b=0)\left(\frac{w_{u}}{w_{s}}\right)^{\alpha+\beta}$

$$
\begin{aligned}
& \frac{(1-\alpha-\beta)\left[(-h)\left\{\beta_{m}(1+r)-w s\right\}+w s \beta_{m}\right]}{(-h)\left[(1-\alpha-\beta) \beta_{n m}-\gamma w_{s}\right]+\gamma w s \beta_{m}} \gtreqless \frac{(1-\alpha-\beta)[(2+r)]}{\gamma}\left(\frac{\mathrm{w}_{u}}{\mathrm{w}_{\mathrm{s}}}\right)^{\alpha+\beta} \\
& \left(\frac{\mathrm{w}_{u}}{\mathrm{w}_{\mathrm{s}}}\right)^{\alpha+\beta}<\frac{(2+r)\left[(-h)\left\{(1-\alpha-\beta) \beta_{n m}-\gamma w_{s}\right\}+\gamma w s \beta_{m}\left\{\beta_{m}(1+r)-w s\right\}+w s \beta_{m}\right]}{\gamma\left[(-h)\left\{\beta_{m}(1+r)-w s\right\}+w s \beta_{m}\right.}
\end{aligned}
$$

If this condition is satisfied, at bequest level $=0, S^{*}(b=0)<S^{u n}$

$$
(b=0)\left(\frac{w_{u}}{w_{\mathrm{s}}}\right)^{\alpha+\beta}
$$

At the intersection, $\mathrm{b}=\mathrm{h}$, we prove if $S^{*}(b=h) \gtreqless S^{u n}(b=h)\left(\frac{\mathrm{w}_{\mathrm{u}}}{\mathrm{w}_{\mathrm{s}}}\right)^{\alpha+\beta}$

$$
\begin{aligned}
& \frac{\left.(1-\alpha-\beta) w s \beta_{m}\right]}{\gamma w s \beta_{m}} \gtreqless \frac{(1-\alpha-\beta)\left[h(1+r)+\mathrm{w}_{u}(2+r)\right]}{\gamma \mathrm{w}_{u}}\left(\frac{\mathrm{w}_{u}}{\mathrm{w}_{\mathrm{s}}}\right)^{\alpha+\beta} \\
& 1 \gtreqless \frac{\left[h(1+r)+\mathrm{w}_{u}(2+r)\right]}{\mathrm{w}_{u}}\left(\frac{\mathrm{w}_{u}}{\mathrm{w}_{\mathrm{s}}}\right)^{\alpha+\beta} \\
& \left(\frac{\mathrm{w}_{s}}{\mathrm{w}_{\mathrm{u}}}\right)^{\alpha+\beta}>\frac{\left[h(1+r)+\mathrm{w}_{u}(2+r)\right]}{\mathrm{w}_{u}}
\end{aligned}
$$

Or

$$
\mathrm{W}_{\mathrm{S}}>\left[\frac{\left\{(1+r)+\mathrm{w}_{u}(2+r)\right\}}{\mathrm{w}_{u}}\right]^{\frac{1}{\alpha+\beta}} \cdot \mathrm{w}_{u}
$$

Thus, at the intersection $b=h, S^{*}>\operatorname{Sun}\left(\frac{w_{u}}{w_{s}}\right)^{\alpha+\beta}$. Due to this binding condition, even if the condition, $S^{*}(b=0)<S^{u n}(b=0)\left(\frac{w_{u}}{w_{s}}\right)^{\alpha+\beta}$ is not satisfied, it will not change our results. 


\section{Appendix G}

In this appendix, we will show the calculations for the long-run equilibrium of unskilled as well as the skilled individuals. This will be calculated using optimal value of bequest and the income which corresponds to each category of workers. This is shown below as:

Long-run equilibrium of an unskilled individual is:

$$
\begin{aligned}
& \mathrm{b}=\mathrm{b}_{\mathrm{t}+1} \\
& \mathrm{~b}=\beta\left(\mathrm{y}_{\mathrm{t}+1}\right) \\
& \mathrm{b}=\beta\left[\mathrm{b}(1+\mathrm{r})+\mathrm{w}_{\mathrm{u}}(2+\mathrm{r})\right] \\
& \mathrm{b}-\beta \mathrm{b}(1+\mathrm{r})=\beta \mathrm{w}_{\mathrm{u}}(2+\mathrm{r}) \\
& \mathrm{b}=\frac{\beta[\mathrm{wu}(2+\mathrm{r})]}{1-\beta b(1+r)}=\mathrm{b}_{\mathrm{u}} \text { or } \dot{\mathrm{x}}^{\mathrm{un}}
\end{aligned}
$$

Long-run equilibrium of skilled individual is:

$$
\begin{aligned}
& \mathrm{b}=\mathrm{b}_{\mathrm{t}+1} \\
& \mathrm{~b}=\beta\left(\mathrm{y}_{\mathrm{t}+1}\right) \\
& \mathrm{b}=\beta\left[(\mathrm{b}-\mathrm{h})(1+\mathrm{r})+\mathrm{w}_{\mathrm{s}}\right] \\
& \mathrm{b}-\beta \mathrm{b}(1+\mathrm{r})=\beta\left[\mathrm{w}_{\mathrm{s}}-\mathrm{h}(1+\mathrm{r})\right] \\
& \mathrm{b}=\frac{\beta[\mathrm{ws}-\mathrm{h}(1+\mathrm{r})]}{1-\beta b(1+r)}=\mathrm{b}_{\mathrm{s}} \text { or } \dot{\mathrm{x}}^{\mathrm{sk}}
\end{aligned}
$$

Finding the critical point, $g_{s}{ }^{*}$

$$
\begin{aligned}
& \mathrm{b}=\beta(S)^{*} \\
& \mathrm{~b}=\beta\left[\frac{(1-\alpha-\beta)\left[(b-h)\left\{\beta_{m}(1+r)-w s\right\}+w s \beta_{m}\right]}{(b-h)\left[(1-\alpha-\beta) \beta_{n m}-\gamma w_{s}\right]+\gamma w s \beta_{m}}\right] \\
& \mathrm{b}\left[(b-h)\left[(1-\alpha-\beta) \beta_{n m}-\gamma w_{s}\right]+\gamma w s \beta_{m}\right]=\beta(1-\alpha- \\
& \beta)\left[\left[(b-h)\left\{\beta_{m}(1+r)-w s\right\}+w s\left(\beta_{m}\right)\right]\right.
\end{aligned}
$$




$$
\begin{aligned}
& -\mathrm{b}^{2}\left[\gamma w_{s}-(1-\alpha-\beta) \beta_{n m}\right]+\mathrm{b}\left[\mathrm{h}\left\{\gamma w_{s}-(1-\alpha-\beta) \beta_{n m}\right\}-\right. \\
& \left.\beta(1-\alpha-\beta)\left\{\beta_{m}(1+r)-w s\right\}+\gamma w s \beta_{m}\right]+[\beta(1-\alpha- \\
& \left.\beta)(h)\left\{\beta_{m}(1+r)-w s\right\}-\beta(1-\alpha-\beta) w s\left(\beta_{m}\right)\right]
\end{aligned}
$$

Now, we will prove that the positive root will be higher than $\mathrm{h}$ so we will consider the lower/negative root only just like for $f$ threshold.

$$
\begin{aligned}
& g_{\text {spositive }^{*}} \gtreqless h \\
& -c \gtreqless a h^{2}+h b \\
& \left.-\beta(1-\alpha-\beta)(h)\left\{\beta_{m}(1+r)-w s\right\}+\beta(1-\alpha-\beta) w s\left(\beta_{m}\right)\right] \gtreqless \\
& \quad\left[-h^{2}\left[\gamma w_{s}-(1-\alpha-\beta) \beta_{n m}\right]+h^{2}\left[\gamma w_{s}-(1-\alpha-\beta) \beta_{n m}\right]\right. \\
& -\mathrm{h} \beta(1-\alpha-\beta)\left\{\beta_{m}(1+r)-w s\right\}
\end{aligned}
$$

$+h \gamma w s \beta_{m}$

$$
\begin{aligned}
& \beta(1-\alpha-\beta) w s \beta_{m} \gtreqless h \gamma w s \beta_{m} \\
& \beta(1-\alpha-\beta) \gtreqless h \gamma
\end{aligned}
$$

L.H.S > R.H.S thus, we ignore the positive root.

$$
\begin{aligned}
& g_{\text {snegative }}{ }^{*} \gtreqless h \\
& 2 a c \gtreqless 2 a^{2} h^{2}+b^{2}+2 a h b \\
& -2\left[\gamma w_{s}-(1-\alpha-\beta) \beta_{n m}\right] \cdot \beta(1-\alpha-\beta)(h)\left\{\beta_{m}(1+r)-w s\right\} \\
& +2\left[\gamma w_{s}\right. \\
& \left.-(1-\alpha-\beta) \beta_{n m}\right] \cdot\left[\beta(1-\alpha-\beta) w s\left(\beta_{m}\right)\right] \\
& \gtreqless \\
& +2 h^{2}\left[\gamma w_{s}-(1-\alpha-\beta) \beta_{n m}\right]^{2}+h^{2}\left\{\gamma w_{s}-(1-\alpha-\right. \\
& \text { B) } \left.\beta_{n m}\right\}^{2}+\beta^{2}(1-\alpha-\beta)^{2}\left\{\beta_{m}(1+r)-w s\right\}^{2}+\gamma^{2} w_{s}{ }^{2} \beta_{m}{ }^{2} \\
& -2 \mathrm{~h} \beta(1-\alpha-\beta)\left\{\beta_{m}(1+r)-w s\right\} .\left\{(1-\alpha-\beta) \beta_{n m}-\right. \\
& \left.\gamma w_{s}\right\}+2 h\left[\gamma w_{s}-(1-\alpha-\beta) \beta_{n m}\right] \gamma w_{s} \beta_{m}-2 \beta(1-\alpha- \\
& \beta)\left\{\beta_{m}(1+r)-w s\right\} \gamma w_{s} \beta_{m}-2 h^{2}\left[\gamma w_{s}-(1-\alpha-\beta) \beta_{n m}\right]^{2}- \\
& 2 h\left[\gamma w_{s}-(1-\alpha-\beta) \beta_{n m}\right] \gamma w_{s} \beta_{m}+2 h\left[\gamma w_{s}-(1-\alpha-\right. \\
& \left.\beta) \beta_{n m}\right] \cdot \beta(1-\alpha-\beta)(h)\left\{\beta_{m}(1+r)-w s\right\}
\end{aligned}
$$

Simplifying the expression: 


$$
\begin{gathered}
-2\left[\gamma w_{s}-(1-\alpha-\beta) \beta_{n m}\right] \cdot\left[\beta(1-\alpha-\beta)(h)\left\{\beta_{m}(1+r)-w s\right\}\right. \\
\left.-\beta(1-\alpha-\beta) w s\left(\beta_{m}\right)\right] \\
\gtreqless \\
\left.h^{2}(1-\alpha-\beta) \beta_{n m}-\gamma w_{s}\right\}^{2}+\beta^{2}(1-\alpha-\beta)^{2}\left\{\beta_{m}(1+r)-w s\right\}^{2}+ \\
\gamma^{2} w_{s}{ }^{2} \beta_{m}{ }^{2}-2 \beta(1-\alpha-\beta)\left\{\beta_{m}(1+r)-w s\right\} \gamma w_{s} \beta_{m}
\end{gathered}
$$

Since $\gamma w_{s}>(1-\alpha-\beta) \beta_{n m}$, we get:

\section{L.H.S < R.H.S}

Therefore, we will consider the negative root which is:

$$
\begin{aligned}
& \frac{\left[h\left\{\gamma w_{s}-(1-\alpha-\beta) \beta_{n m}\right\}-\beta(1-\alpha-\beta)\left\{\beta_{m}(1+r)-w_{s}\right\}+\gamma w_{s} \beta_{m}\right]}{2\left[\gamma w_{s}-(1-\alpha-\beta) \beta_{n m}\right]} \\
& \frac{+\sqrt{h^{2}\left\{\gamma w_{s}-(1-\alpha-\beta) \beta_{n m}\right\}^{2}+\beta^{2}(1-\alpha-\beta)^{2}\left\{\beta_{m}(1+r)-w_{s}\right\}^{2}+\gamma^{2} w_{s}{ }^{2} \beta_{m}{ }^{2} \cdots}}{2\left[\gamma w_{s}-(1-\alpha-\beta) \beta_{n m}\right]} \\
& \frac{\sqrt{-2 h\left\{\gamma w_{s}-(1-\alpha-\beta) \beta_{n m}\right\} . \beta(1-\alpha-\beta)\left\{\beta_{m}(1+r)-w_{s}\right\}+h\left\{\gamma w_{s}-(1-\alpha-\beta) \beta_{n m}\right\} \gamma w_{s} \beta_{m} .}}{2\left[\gamma w_{s}-(1-\alpha-\beta) \beta_{n m}\right]} \\
& \frac{\sqrt{-2 \gamma w_{s} \beta_{m} \beta(1-\alpha-\beta)\left\{\beta_{m}(1+r)-w_{s}\right\}+4\left\{\gamma w_{s}-(1-\alpha-\beta) \beta_{n m}\right\} \ldots}}{2\left[\gamma w_{s}-(1-\alpha-\beta) \beta_{n m}\right]} \\
& \frac{\sqrt{\left.\cdot \beta(1-\alpha-\beta) h\left\{\beta_{m}(1+r)-w_{s}\right\}+4\left\{\gamma w_{s}-(1-\alpha-\beta) \beta_{n m}\right\} w_{s} \beta_{m}\right\}}}{2\left[\gamma w_{s}-(1-\alpha-\beta) \beta_{n m}\right]}
\end{aligned}
$$




\section{Appendix $\mathbf{H}$}

In this appendix, we will perform the comparative analysis on $g_{s}{ }^{*}$ to see which variable can reduce these short-run and long-run equilibriums.

We will derivate the first part of the fraction:

$$
\frac{\partial \mathrm{gs} *}{\partial \mathrm{w}_{\mathrm{s}}}=-\mathrm{ve}
$$

Hence, the derivative is negative. Higher skilled wages decrease the long-run threshold.

\section{Shorter proof of the derivation:}

Since, this is lower root so we simplify it accordingly to find the relationship:

$$
\begin{aligned}
& \frac{-b-\sqrt{b^{2}-4 a c}}{2 a} \gtreqless 0 \\
& -b \gtreqless \sqrt{b^{2}-4 a c} \\
& b^{2} \gtreqless b^{2}-4 a c \\
& 0 \gtreqless-4 a c \\
& \frac{\partial f}{\partial \beta_{n m}}=0 \gtreqless-4 a c \\
& b^{2}(1+r)\left(\frac{w_{u}}{w_{s}}\right)^{\alpha+\beta}\left\{\gamma w_{s}-(1-\alpha-\beta) \beta_{n m}\right\} \\
& +b\left[\gamma w_{u}\left\{\beta_{m}(1+r)-w_{s}\right\}-h(1+r)\left(\frac{w_{u}}{w_{s}}\right)^{\alpha+\beta}\left\{\gamma w_{s}-(1-\alpha-\right.\right. \\
& \left.\beta) \beta_{n m}\right\}-(1+r)\left(\frac{w_{u}}{w_{s}}\right)^{\alpha+\beta} \gamma w_{s} \beta_{m}+w u(2+r)\left(\frac{w_{u}}{w_{s}}\right)^{\alpha+\beta}\left\{\gamma w_{s}-\right. \\
& \left.\left.(1-\alpha-\beta) \beta_{n m}\right\}\right] \\
& +\left[-\gamma w_{u} \cdot h\left\{\beta_{m}(1+r)-w_{s}\right\}+\gamma w_{u} w_{s} \beta_{m}-w u(2+r) h\left(\frac{w_{u}}{w_{s}}\right)^{\alpha+\beta}\left\{\gamma w_{s}-\right.\right. \\
& \left.\left.(1-\alpha-\beta) \beta_{n m}\right\}-w u(2+r)\left(\frac{w_{u}}{w_{s}}\right)^{\alpha+\beta} \gamma w_{s} \beta_{m}\right]
\end{aligned}
$$




$$
\begin{gathered}
0 \gtreqless\left[-4(1+r)\left(\frac{w_{u}}{w_{s}}\right)^{\alpha+\beta}\left\{\gamma w_{s}-(1-\alpha-\beta) \beta_{n m}\right\}\right] \cdot\left[-\gamma w_{u} \cdot h\left\{\beta_{m}(1+\right.\right. \\
\left.r)-w_{s}\right\}+\gamma w_{u} w_{s} \beta_{m}-w u(2+r) h\left(\frac{w_{u}}{w_{s}}\right)^{\alpha+\beta}\left\{\gamma w_{s}-\right. \\
\left.\left.(1-\alpha-\beta) \beta_{n m}\right\}-w u(2+r)\left(\frac{w_{u}}{w_{s}}\right)^{\alpha+\beta} \gamma w_{s} \beta_{m}\right]
\end{gathered}
$$

Derivate w.r.t $\beta_{\mathrm{nm}}$

$$
\begin{gathered}
0 \gtreqless-4(1+r)\left(\frac{w_{u}}{w_{s}}\right)^{\alpha+\beta} \cdot \gamma w_{u} \cdot h\left\{\beta_{m}(1+r)-w_{s}\right\}+4(1 \\
+r)\left(\frac{w_{u}}{w_{s}}\right)^{\alpha+\beta} \gamma w_{u} w_{s} \beta_{m} \\
-8 w u(2+r) h\left(\frac{w_{u}}{w_{s}}\right)^{\alpha+\beta^{2}}(1+r)\left\{\gamma w_{s}-(1-\alpha-\beta) \beta_{n m}\right\}(1-\alpha-\beta) \\
-4(1+r)\left(\frac{w_{u}}{w_{s}}\right)^{\alpha+\beta^{2}} w u(2+r) \gamma w_{s} \beta_{m}(1-\alpha-\beta)
\end{gathered}
$$

Since, L.H.S > R.H.S because R.H.S is negative, therefore, derivative is positive

In the short-run, the threshold, $f$, will increase with higher non-monetary cost.

$$
\begin{aligned}
& \frac{\partial g^{*}}{\partial \beta_{n m}}=0 \gtreqless-4 a c \\
& -\mathrm{b}^{2}\left[\gamma w_{s}-(1-\alpha-\beta) \beta_{n m}\right]+\mathrm{b}\left[\mathrm{h}\left\{\gamma w_{s}-(1-\alpha-\beta) \beta_{n m}\right\}-\right. \\
& \left.\beta(1-\alpha-\beta)\left\{\beta_{m}(1+r)-w s\right\}+\gamma w s \beta_{m}\right]+[\beta(1-\alpha- \\
& \left.\beta)(h)\left\{\beta_{m}(1+r)-w s\right\}-\beta(1-\alpha-\beta) w s\left(\beta_{m}\right)\right] \\
& 0 \gtreqless+4\left[\gamma w_{s}-(1-\alpha-\beta) \beta_{n m}\right]\left[\beta ( 1 - \alpha - \beta ) ( h ) \left\{\beta_{m}(1+r)-\right.\right. \\
& \left.w s\}]-4 \beta(1-\alpha-\beta) w s\left(\beta_{m}\right)\right]\left[\gamma w_{s}-(1-\alpha-\beta) \beta_{n m}\right]
\end{aligned}
$$

Derivate w.r.t $\beta_{\mathrm{nm}}$

$$
\begin{aligned}
& 0 \gtreqless-4\left[\beta(1-\alpha-\beta)^{2}(h)\left\{\beta_{m}(1+r)-w s\right\}\right]+4 \beta(1-\alpha- \\
& \left.\beta)^{2} w s\left(\beta_{m}\right)\right] \\
& \left.\left.0 \gtreqless-(h)\left\{\beta_{m}(1+r)-w s\right\}\right]+w s\left(\beta_{m}\right)\right]
\end{aligned}
$$

Simplifying it, we get:

$$
0 \gtreqless h w s+\left(\beta_{m}\right)[w s-h(1+r)]
$$


Since, R.H.S is positive, L.H.S < R.H.S and the derivative is negative In the long-run, the critical threshold, $g_{s}^{*}$ will decrease with a higher nonmonetary cost of social exclusion. 